\title{
Melatonin as an Adjunct to Therapeutic Hypothermia in a Piglet Model of Neonatal Encephalopathy: a Translational Study
}

Nicola J Robertson ${ }^{1,2}$, Kathryn Martinello ${ }^{1}$, Ingran Lingam ${ }^{1}$, Adnan Belltheus ${ }^{1}$, Christopher Meehan ${ }^{1}$, Daniel Alonso-Alconada ${ }^{3}$, Sara Ragab ${ }^{1}$, Alan Bainbridge ${ }^{4}$, Magda Sokolowska ${ }^{4}$, Mohamed Tachrout $^{5}$, Benita Middleton ${ }^{5}$, David Price ${ }^{4}$, Mariya Hristova ${ }^{1}$, Xavier Golay ${ }^{6}$, Annamaria Soliani Raschini $^{7}$, Giancarlo Aquino ${ }^{7}$, Nicola Pelizzi ${ }^{7}$, Fabrizio Facchinetti $^{7}$

1. University College London, London WC1E 6HX

2. Sidra Medicine, Doha, Qatar

3. University of the Basque Country, Leioa, Spain

4. University College London Hospitals NHS Trust

5. Chronobiology Group, Faculty of Health \& Medical Sciences, University of Surrey, Guildford, Surrey GU2 7XH, UK

6. Institute of Neurology, Queen Square, London

7. Chiesi Farmaceutici S.p.A., Parma, Italy

Running Title: Melatonin for Birth Asphyxia 1 (MELBA 1)

Corresponding author:

Nicola J Robertson,

UCL EGA Institute for Women's Health (IfWH),

University College London,

London WC1E $6 \mathrm{HX}$

Direct line: +44 (0)20 76796052

Mobile: +44 (0)7779 248235

E mail: n.robertson@ucl.ac.uk 


\section{ABSTRACT}

Therapeutic hypothermia is only partially protective for neonatal encephalopathy; there is an urgent need to develop treatments that augment cooling. Our objective was to assess safety, efficacy and pharmacokinetics of 5 or $15 \mathrm{mg} / \mathrm{kg} / 24 \mathrm{~h}$ proprietary melatonin formulation administered at $2 \mathrm{~h}$ and $26 \mathrm{~h}$ after hypoxia-ischemia $(\mathrm{HI})$ with cooling in a piglet model. Following moderate cerebral $\mathrm{HI}, 30$ piglets were eligible and randomized to: i) Hypothermia $\left(33.5^{\circ} \mathrm{C}, 2-26 \mathrm{~h}\right)$ and vehicle $\left.(H T+V ; n=13) ; b\right) H T$ and $5 \mathrm{mg} / \mathrm{kg}$ melatonin over $6 \mathrm{~h}$ at $2 \mathrm{~h}$ and $26 \mathrm{~h}$ after $\mathrm{HI}(\mathrm{HT}+\mathrm{Mel}-5 ; \mathrm{n}=4) ; \mathrm{c}) \mathrm{HT}$ and $15 \mathrm{mg} / \mathrm{kg}$ melatonin over $6 \mathrm{~h}$ at $2 \mathrm{~h}$ and $26 \mathrm{~h}$ after $\mathrm{HI}(\mathrm{HT}+\mathrm{Mel}-15 ; \mathrm{n}=13)$. Intensive care was maintained for $48 \mathrm{~h}$; brain MRS was acquired and cell death (TUNEL) evaluated at $48 \mathrm{~h}$. Comparing HT+V with HT+Mel5 and $\mathrm{HT}+\mathrm{Mel}-15$, there was no difference in blood pressure or inotropic support needed, brain Lactate/N Acetyl aspartate at 24 and $48 \mathrm{~h}$ was similar, ATP/phosphate pool was higher for $\mathrm{HT}+\mathrm{Mel}-$ 15 versus $H T+V$ at $24 h(p=0.038)$ but not $48 h$. A localized reduction in TUNEL positive cell death was observed in the sensorimotor cortex in the $15 \mathrm{mg} / \mathrm{kg}$ melatonin group ( $\mathrm{HT}+\mathrm{Mel}-15$ versus $\mathrm{HT}+\mathrm{V}$; $\mathrm{p}<0.003$ ) but not in the $5 \mathrm{mg} / \mathrm{kg}$ melatonin group $(\mathrm{HT}+\mathrm{Mel}-5$ versus $\mathrm{HT}+\mathrm{V} ; \mathrm{p}=0.808)$. Putative therapeutic melatonin levels were reached $8 \mathrm{~h}$ after $\mathrm{HI}\left(10^{4}\right.$ increase from baseline). Mean $\pm \mathrm{SD}$ area under the curve plasma melatonin levels in $\mathrm{HT}+\mathrm{V}, \mathrm{HT}+\mathrm{Mel}-5$ and $\mathrm{HT}+\mathrm{Mel}-15$ were $0.015 \pm 0.012$ $\mathrm{mg}^{*} \mathrm{~h} / \mathrm{L}, 136 \pm 61 \mathrm{mg}{ }^{*} \mathrm{~h} / \mathrm{L}$ and $555 \pm 266 \mathrm{mg}{ }^{*} \mathrm{~h} / \mathrm{L}$ respectively; the peak plasma melatonin level after the first infusion was $0.0014 \pm 0.0012 \mathrm{mg} / \mathrm{L}, 3.97 \pm 1.53 \mathrm{mg} / \mathrm{L}$ and $16.8 \pm 8.3 \mathrm{mg} / \mathrm{L}$, respectively. $15 \mathrm{mg} / \mathrm{kg}$ melatonin started $2 \mathrm{~h}$ after $\mathrm{HI}$ with cooling was well tolerated and augmented hypothermic protection in sensorimotor cortex; protection was dose dependent. Earlier attainment of therapeutic plasma melatonin levels may optimize protection by targeting initial events of reperfusion injury. The time window for intervention with melatonin, as adjunct therapy with cooling, is likely to be narrow and should be considered in designing future clinical studies. 


\section{INTRODUCTION}

Intrapartum-related insults at full term, such as hypoxia-ischemia $(\mathrm{HI})$, are the $3^{\text {rd }}$ leading cause of child death across the world (Liu et al., 2016). Each year, over 0.7 million affected newborns die and 1.15 million newborns develop acute disordered brain function known as neonatal encephalopathy (NE) (Kurinczuk et al., 2010). The incidence of NE in Western Europe and North America is around 1-3/1000 term births depending on the definitions used (Jenkins et al., 2013). Although improvements in care might prevent NE and neonatal death in some cases (NPEU, 2017), many cases cannot be prevented and therapies are limited. Therapeutic hypothermia (HT) initiated within $6 \mathrm{~h}$ of birth improves outcome, yet despite this therapy $44-53 \%$ of infants with NE die or suffer moderate to severe disabilities including cerebral palsy, developmental delay, epilepsy and visual impairment (Edwards et al., 2010; Jacobs et al., 2011). Attempts to increase brain protection with deeper and longer cooling (Alonso-Alconada et al., 2015; Shankaran et al., 2014; Shankaran et al., 2017) suggest that current clinical cooling protocols are optimal and that other therapies which augment hypothermic neuroprotection in NE are needed (Robertson et al., 2012).

In a comparative review of potential neuroprotective agents that might augment HT for NE, melatonin ( $\mathrm{N}$-acetyl-5-methoxytryptamine) showed most promise in terms of efficacy and safety (Robertson et al., 2012). A strong body of evidence suggests that melatonin is neuroprotective for acute $\mathrm{HI}$ injury in the adult (Macleod et al., 2005) and neonatal brain (Husson et al., 2002) mediated by its anti-oxidant, anti-apoptotic and anti-inflammatory properties (Kilic et al., 2005; Luchetti et al., 2010). As HT is routine for term NE, it is important to assess if melatonin augments protection given by cooling and what plasma melatonin levels are safe and optimal. In a neonatal piglet model of perinatal asphyxia we previously showed that $30 \mathrm{mg} / \mathrm{kg} / 24 \mathrm{~h}$ intravenous melatonin, started at 10 mins after $\mathrm{HI}$ and infused over $6 \mathrm{~h}$ with ethanol excipient was well tolerated, improved brain energy metabolism on magnetic resonance spectroscopy (MRS) and significantly reduced cell death in grey and white matter compared to cooling alone (Robertson et al., 2013); in that study, maximum peak melatonin levels $\left(\mathrm{C}_{\max }\right)$ were $17-31 \mathrm{mg} / \mathrm{L}(74-134 \mu \mathrm{M})$. A recent in vitro study using organotypical hippocampal brain slices confirmed the synergy between cooling and melatonin for protection and concurred with these levels for optimal neuroprotection; melatonin reduced cell death in a concentration-dependent manner $(1-100 \mathrm{uM})$ with a half maximal effective concentration $\left(E_{50}\right)$ of about $25 \mu \mathrm{M}$ (equivalent to $5.8 \mathrm{mg} / \mathrm{L}$ ) (Carloni et al., 2018 ).

Melatonin crosses the blood brain barrier and has an excellent safety profile with no known adverse effects (Buscemi et al., 2006; Jahnke et al., 1999). In small neonatal clinical studies, melatonin improved outcomes in sepsis (Gitto et al., 2001), prematurity (Gitto et al., 2004b), and perinatal asphyxia (Fulia et al., 2005). As melatonin is sparingly soluble in aqueous vehicles, solubility enhancers are needed, such as ethanol or other excipients, to obtain a solution with the desired concentration. Ethanol, in particular, could have been a confounding factor in previous studies 
(Drury et al., 2014; Fulia et al., 2005; Welin et al., 2007; Yawno et al., 2017) since low doses of ethanol can have neuroprotective effects against ischemia/reperfusion injury (Su et al., 2017). Babies in the neonatal intensive care around the world are commonly exposed to potentially neurotoxic excipients, including ethanol; efforts are urgently needed to understand pharmacokinetics, long-term effects and safety of ethanol in excipients (Marek and Kraft, 2014) and potentially reduce this exposure (Whittaker et al., 2009).

In the present study, an ethanol-free, highly concentrated $(5 \mathrm{mg} / \mathrm{ml})$ proprietary melatonin formulation was developed using excipients considered safe for use in neonates (Int. pat. appl. PCT/EP2018/056423); pilot pharmacokinetic studies showed that $15 \mathrm{mg} / \mathrm{kg}$ of this melatonin formulation was well tolerated and achieved equivalent plasma levels to the $30 \mathrm{mg} / \mathrm{kg}$ of the previously used ethanol-containing melatonin formulation in piglets (Robertson et al., 2013). We hypothesized that brain protection would be dependent on the melatonin dose and the area under the curve (AUC) melatonin within the therapeutic range. Our objective was to assess safety, efficacy and pharmacokinetics of an ethanol-free melatonin formulation in a newborn piglet model of brain injury, starting the infusion at a time compatible with the clinical practice ( $2 \mathrm{~h}$ after $\mathrm{HI}$ ). This model replicates neonatal intensive care with monitoring and control of physiological and metabolic parameters. This model also has strong similarities to newborn infants with NE in terms of the timing of the evolution of injury after HI (Azzopardi et al., 1989; Lorek et al., 1994), pattern of injury, neuropathology and cerebral MRS. The efficacy of melatonin protection over cooling alone was assessed using: (i) Cerebral MRS biomarkers, proton ( $\left.{ }^{1} \mathrm{H}\right)$ MRS lactate/N acetyl aspartate (NAA) (Mitra et al., 2018) and phosphorus-31 ( $\left.{ }^{31} \mathrm{P}\right)$ MRS for phosphocreatine/inorganic phosphate (PCr/Pi) and ATP/exchangeable phosphate pool (epp) (Azzopardi et al., 1989); (ii) aEEG background activity recovery over $48 \mathrm{~h}$, a strong predictor of outcome in babies with NE (van Rooij et al., 2005); and (iii) Histological assessment of cell death in 8 brain regions using TUNEL at $48 \mathrm{~h}$ after $\mathrm{HI}$. 


\section{MATERIAL AND METHODS}

\section{Sample size calculation}

Our primary outcomes were cerebral lactate/NAA, ATP/epp and TUNEL positive cells. Previous work with our model with melatonin at 10 mins after $\mathrm{HI}$ has suggested that the change in lactate/NAA during $48 \mathrm{~h}$ varied between cooling and cooling plus melatonin by $0.5 \mathrm{U}$ with a standard deviation of $0.3 \mathrm{U}$ (log scale). Assuming a similar effect magnitude with melatonin and similar variability at $48 \mathrm{~h}$ and with $5 \%$ significance and $80 \%$ power, at least 9 subjects are needed in each group. A delay in the administration of melatonin from 10 mins to $2 \mathrm{~h}$ was likely to reduce the effect size and so the group size was increased to $n=13$. Interim analysis was planned to assess futility of treatment after 20 cases.

\section{Animal experiments and surgical preparation}

All animal experiments were approved by the Ethics Committee of UCL and performed according to the UK Home Office Guidelines [Animals (Scientific Procedures) Act, 1986]. The study complies with the ARRIVE guidelines. Piglets were anesthetised and surgically prepared as described previously (Lorek et al., 1994). Criteria for entry into the study were: (i) normal aEEG /EEG at baseline after surgery; (ii) normal ${ }^{1} \mathrm{H}$ MRS at baseline with only detectable lactate seen on the MR spectrum; (iii) no pyrexia; (iv) recovery of the ${ }^{31} \mathrm{P}$ MRS NTP/epp to $>70 \%$ baseline after cerebral $\mathrm{HI}$ to ensure standardization of the insult severity.

The study time-line is shown in Figure 1. Anaesthesia was induced by $4 \% \mathrm{v} / \mathrm{v}$ isoflurane through a facemask for around 5 minutes to facilitate tracheostomy and intubation. Throughout the surgery, isoflurane was maintained at $2.8-3 \%$ guided by peripheral oxygen saturation monitoring (Nonin Medical, Plymouth, MN, USA) and animal's response to stimulation. Following tracheostomy, a suitable size of endotracheal tube (Smiths Medical, Ashford, Kent, UK) was fixed and the piglet was mechanically ventilated (SLE 2000 infant ventilator, Surrey, UK). Ventilator settings were adjusted to maintain partial pressure of oxygen $\left(\mathrm{PaO}_{2}\right)$ at $8-13 \mathrm{kPa}$ and carbon dioxide $\left(\mathrm{PaCO}_{2}\right)$ at $4.5-$ $6.5 \mathrm{kPa}$, allowing for temperature and fraction of inspired oxygen $\left(\mathrm{FiO}_{2}\right)$ correction of the arterial blood sample.

After the airway was secured, both common carotid arteries were surgically isolated at the level of the fourth cervical vertebra and a vascular occluder (OC2A, In Vivo Metric, Healdsburg, CA, USA) was placed on each side. After completion of surgery, inspired isoflurane concentration was maintained at $2 \% \mathrm{v} / \mathrm{v}$.

A 4 French double lumen umbilical venous catheter (Vygon, Swindon, UK) was inserted for infusion of maintenance fluids ( $10 \%$ dextrose, $60 \mathrm{ml} / \mathrm{kg} /$ day, reduced to $40 \mathrm{ml} / \mathrm{kg} / \mathrm{day}$ post insult), fentanyl $(3 \mu \mathrm{g} / \mathrm{kg} / \mathrm{h})$ and antibiotics (benzylpenicillin $50 \mathrm{mg} / \mathrm{kg}$ every $12 \mathrm{~h}$ and gentamicin $2.5 \mathrm{mg} / \mathrm{kg}$ every 
24h). A 2.5 French umbilical arterial catheter (Vygon) was inserted for continuous monitoring of heart rate and arterial blood pressure (MABP), and intermittent blood sampling was used to measure $\mathrm{PaO}_{2}, \mathrm{PaCO}_{2}, \mathrm{pH}$, electrolytes, glucose and lactate (Abbot Laboratories, UK). Arterial lines were maintained by infusing $0.9 \%$ saline solution $(0.3 \mathrm{~mL} / \mathrm{h})$ with $1 \mathrm{IU} / \mathrm{mL}$ heparin sodium.

Intensive care support for the animal throughout the $48 \mathrm{~h}$ experiment and complications (e.g. hypotension, seizures, hyperkalemia) managed in accordance with local neonatal intensive care guidelines. All piglets received continuous physiological monitoring (SA instruments). To maintain the MABP above $40 \mathrm{~mm} \mathrm{Hg}$, bolus infusions of $0.9 \%$ saline (Baxter; $10 \mathrm{ml} / \mathrm{kg}$ ), dopamine (5-20 $\mu \mathrm{g} / \mathrm{kg} / \mathrm{min})$, dobutamine $(5-20 \mu \mathrm{g} / \mathrm{kg} / \mathrm{min})$, noradrenaline $(0.1-1 \mu \mathrm{g} / \mathrm{kg} / \mathrm{min})$ and adrenaline $(0.1-1.5$ $\mu \mathrm{g} / \mathrm{kg} / \mathrm{min}$ ) were used as required by a NICU trained clinician. High serum lactate was treated by optimizing oxygenation and $0.45 \%$ saline bolus infusions. Hyperkalemia $(>7.0 \mathrm{mmol} / \mathrm{l})$ was treated with $4 \mu \mathrm{g} / \mathrm{kg}$ salbutamol $(10 \mu \mathrm{g} / \mathrm{ml})$ over $10 \mathrm{~min}$. Rectal temperature was maintained at $33.5^{\circ} \mathrm{C}$ from $2-26 \mathrm{~h}$ using a cooling water mattress (Tecotherm); rewarming occurred at $0.5^{\circ} \mathrm{C} /$ hour. For the remainder of the study rectal temperature was maintained in the normothermic range $\left(38.0-39.0^{\circ} \mathrm{C}\right)$ using a radiant warmer during surgery and subsequently a heating water mattress (Tecotherm).

\section{MR Methods}

Animals were nursed prone in a stereotactic frame built within a MR compatible transport incubator which was purpose-built. Piglets were positioned within the bore of 9.4 Tesla Agilent MR scanner. ${ }^{1} \mathrm{H}$ and ${ }^{31} \mathrm{P}$ MRS data were acquired at baseline (for all piglets $\left.n=30\right)$ and at $24 h(H T+V n=11$, $\mathrm{HT}+\mathrm{Mel}-5 \mathrm{n}=4, \mathrm{HT}+\mathrm{Mel}-15 \mathrm{n}=13)$ and 48h (HT+V n=8, HT+Mel-5 n=4, HT+Mel-15 n=12) after cerebral $\mathrm{HI}$.

For ${ }^{31} \mathrm{P}$ MRS a $7 \mathrm{~cm} \times 5 \mathrm{~cm}$ elliptical transmit-receive MRS surface coil tuned to the ${ }^{31} \mathrm{P}$ resonant frequency was positioned above the head. ${ }^{31} \mathrm{P}$ MRS was acquired with $1 \mathrm{~min}$ resolution using a nonlocalized single-pulse acquisition. MRS data were analyzed using the Advanced Method for Accurate, Robust and Efficient Spectral fitting of MRS data with use of prior knowledge (AMARES) (Vanhamme et al., 1997) as implemented in the jMRUI software. Prior knowledge of NTP multiplet structure was used. Nucleotide tri-phosphate (NTP) is predominately ATP and the latter contributes approximately $70 \%$ of the NTP signal (Mandel and Edel-Harth, 1966). Thus NTP changes during this experiment predominately reflected ATP changes. Pi was fitted using 4 separate components and $\mathrm{PCr}$ with a single component. The following peak-area ratios were calculated: $\mathrm{Pi} / \mathrm{epp}, \mathrm{PCr} / \mathrm{epp}$, and NTP/epp where epp $=$ exchangeable phosphate pool $=\mathrm{Pi}+\mathrm{PCr}+2 \gamma-\mathrm{NTP}+\beta-\mathrm{NTP}$.

For ${ }^{1} \mathrm{H}$ MRS, data were collected from voxels located in the dorsal right subcortical white matter at the centrum semiovale level (white matter voxel, $8 \times 8 \times 15 \mathrm{~mm}$ ) and in the deep grey matter centered on both lateral thalami (deep grey matter voxel, 15x15x10mm) using a combination of a $65 \times 55 \mathrm{~mm}$ elliptical receive surface coil, a $150 \mathrm{~mm}$ diameter transmit volume coil and a LASER acquisition (TR 
$=5000 \mathrm{~ms}, \mathrm{TE}=288 \mathrm{~ms}, 128$ averages). Spectra were analyzed using AMARES as implemented in the jMRUI software and the lactate/NAA peak area ratio was calculated.

\section{Cerebral hypoxia-ischemia $(H I)$ and randomization}

$\mathrm{HI}$ was induced inside the MR scanner by remotely inflating the vascular occluders around both common-carotid arteries, and simultaneously reducing $\mathrm{FiO}_{2}$ to $6 \%$ (vol/vol). During $\mathrm{HI}$ the $\beta$-NTP peak height was continuously monitored using in-house Matlab (Mathworks) software. At the point at which $\beta$-NTP had fallen to $50 \%$ of its baseline value, $\mathrm{FiO}_{2}$ was increased to $9 \%$. When $\beta$-NTP fell to $40 \%$ baseline height the inspired oxygen fraction was titrated to keep the $\beta$-NTP peak height between $30 \%$ and $40 \%$ of its original height for a period of 12.5 minutes. At the end of $\mathrm{HI}$ the carotid arteries were de-occluded and the $\mathrm{FiO}_{2}$ returned to $21 \%$. Insult severity was calculated (Faulkner et al., 2011).

Following resuscitation, piglets were excluded if the $\beta$-NTP peak did not recover to $>70 \%$ baseline within $1 \mathrm{~h}$ of resuscitation. Eligible piglets were randomized (computer generated randomization) into 3 groups $(\mathrm{HT}+\mathrm{V}, \mathrm{HT}+\mathrm{Mel}-5, \mathrm{HT}+\mathrm{Mel}-15)$ until interim analysis and then 2 groups $(\mathrm{HT}+\mathrm{V}$ or $\mathrm{HT}+\mathrm{Mel}-15)$ (Figure 1).

\section{Melatonin delivery}

Vehicle and proprietary melatonin vials (batch\# P571-03 and batch\# P571-07PL) were stored at room temperature. The proprietary melatonin formulation was administered intravenously; for the $\mathrm{HT}+\mathrm{Mel}-5$ group the infusion rate was $0.33 \mathrm{ml} / \mathrm{hr}$ over $6 \mathrm{~h}$ for a typical $2 \mathrm{~kg}$ piglet; for the HT+Mel- 15 group the infusion rate was $1 \mathrm{ml} / \mathrm{h}$ over $6 \mathrm{~h}$ for a typical $2 \mathrm{~kg}$ piglet. The vehicle was administered at $1 \mathrm{ml} / \mathrm{h}$ over $6 \mathrm{~h}$ for a typical $2 \mathrm{~kg}$ piglet.

\section{aEEG}

After surgical preparation, multichannel six-lead EEG monitoring (Nicolet, Care Fusion, Wisconsin, USA) was acquired at baseline and between MRS data acquisitions. Filtered amplitude-integrated EEG (aEEG) recordings were classified according to the pattern classification (Hellström-Westas et al., 1995). A score of 0 was flat trace; 1 , continuous low voltage; 2, burst suppression; 3 , discontinuous normal voltage; and 4, continuous normal voltage, at baseline and then every hour after HI. Scoring was performed at hourly intervals independently by two clinicians (IL, KM) blinded to the treatment allocation. Hourly aEEG scores were averaged in $6 \mathrm{~h}$ time epochs and mean differences analysed for significance between study groups. Seizure activity was quantified. Electrographic seizures were treated with Phenobarbitone, initially $20 \mathrm{mg} / \mathrm{kg}$, followed by $10 \mathrm{mg} / \mathrm{kg}$ for subsequent seizures, up to a maximum $40 \mathrm{mg} / \mathrm{kg}$. 


\section{Blood and CSF for Melatonin Pharmacokinetics}

Blood was sampled at baseline and 1, 3, 6, 12, 18, 26, 27, 29, 32, 38, 44, 50h after the first melatonin infusion at $2 \mathrm{~h}$. Blood samples were collected in lithium/heparin tubes and centrifuged immediately after collection. Plasma was separated and then stored at $-20^{\circ} \mathrm{C}$ before analysis. When piglets were euthanized, in most cases a terminal cerebrospinal fluid (CSF) sample was collected and melatonin levels analyzed.

\section{Melatonin Assay}

Plasma melatonin levels were measured by Stockgrand Ltd following a modification of Fraser (Fraser et al., 1983). Samples were subjected to chloroform extraction, solvent was removed by evaporation under oxygen free nitrogen. Extracted melatonin was resuspended in assay buffer and further diluted to give concentrations within the standard curve range of $0-500 \mathrm{pg} / \mathrm{ml}$. Pig plasma quality control samples and spiked pig plasma were included in each assay. Limit of detection of the assay was $3 \mathrm{pg} / \mathrm{ml}$. Quality control values were $27.8 \pm 3.4 \mathrm{pg} / \mathrm{ml}$ coefficient of variation $(\mathrm{CV})=12.3 \% ; 73.5 \pm 7.9 \mathrm{pg} / \mathrm{ml} \mathrm{CV}=10.7 \% ; 118.1 \pm 12.7 \mathrm{pg} / \mathrm{ml} \mathrm{CV}=10.7 \% ; 214.2 \pm$ $27.6 \mathrm{pg} / \mathrm{ml} \mathrm{CV}=12.9 \% ; 137.9 \pm 21.1 \mathrm{ng} / \mathrm{ml} \mathrm{CV}=15.3 \% ; 256.1 \pm 38.9 \mathrm{ng} / \mathrm{ml} \mathrm{CV}=15.2 \% ; 550.0$ $\pm 37.2 \mathrm{ng} / \mathrm{ml} \mathrm{CV}=6.8 \%$.

\section{Brain histology}

At $48 \mathrm{~h}$ after $\mathrm{HI}$, piglets were euthanized with pentobarbital and the brain was fixed by cardiac perfusion with cold $4 \%$ paraformaldehyde, dissected out and post-fixed at $4^{\circ} \mathrm{C}$ in $2 \%$ paraformaldehyde for 7 days. Coronal slices ( $5 \mathrm{~mm}$ thick) of the right hemisphere, starting from anterior to the optic chiasma, were embedded in paraffin, sectioned to $8 \mu \mathrm{m}$ thickness and stained with hematoxylin and eosin to validate the bregma for analysis. For each animal, 2 sections (bregma 00 and -2.0) were stained and 8 different brain regions were examined (Figure 2).

\section{TUNEL (8 brain regions)}

To assess cell death, brain sections were stained for nuclear DNA fragmentation using histochemistry with transferase mediated biotinylated d-UTP nick end-labelling (TUNEL) as previously described(Robertson et al., 2013). Briefly, TUNEL sections were pre-treated in $3 \%$ hydrogen peroxide, subjected to a protease $\mathrm{K}$ pre-digestion (Promega, Southampton, UK) and incubated with TUNEL solution (Roche, Burgess Hill, UK). TUNEL was visualized using avidinbiotinylated horseradish complex (ABC, Vector Laboratories, Peterborough, UK) and diaminobenzidine/ $\mathrm{H}_{2} \mathrm{O}_{2}$ (DAB, Sigma, Poole, UK) enhanced with $\mathrm{CoSO}_{4}$ and $\mathrm{NiCl}_{2}$. TUNEL sections were dehydrated and cover-slipped with DPX (VWR, Leighton Buzzard, UK). For each animal and brain region, TUNEL-positive nuclei were counted at two levels, and from 8 regions with 3 fields per region (Figure 2) by an investigator blind to the treatment group and the average converted into counts per $\mathrm{mm}^{2}$. 


\section{GFAP (sensorimotor and cingulate cortex only)}

The levels of astroglial activation was assessed via GFAP immunoreactivity (DAKO Z0334, dilution $1: 1000$ ). Mean \pm SD of optical luminosity values were measured in 3 non-overlapping fields ( $x 20$ magnification) of the different brain regions of GFAP stained slides using Optimas 6.5 image software. SD was subtracted from the mean of each field and the resulting value was subtracted from the value obtained from the surround glass.

\section{Iba-1 (sensorimotor and cingulate cortex only)}

The activation state of Iba-1 positive cells (Wako 019-19741, dilution 1:250) was assessed by scoring the process number, process complexity (primary, secondary and tertiary) and relative intensity of the soma staining from 0 to 4 (score 0 , thin process with tertiary branches and able to visualise the cresyl violet counterstain through the Iba-1 of the soma; 1 , tertiary processes but increased staining intensity of the soma; 2 , reduced numbers of tertiary processes and thickening of secondary processes with intense enlarged soma; 3 , loss of secondary processes and short thickened primary with intense soma; 4 , no process and intensely stained soma). Scores were taken of 4 cells/FOV at x20 magnification (at set positions from the corners of the image) for a total of 24 cells/region/animal. Two investigators, blinded to treatment group, scored each image independently and their scores were averaged.

\section{Cleaved caspase 3 (sensorimotor and cinqulate cortex only)}

The sections were processed for antigen retrieval $(800-\mathrm{mW}$ microwave irradiation in $0.1 \mathrm{M}$ citrate buffer, $10 \mathrm{~min}$ ), followed by overnight incubation with primary rabbit antibody against activated caspase 3 (Cell signalling 9661 L, dilution 1:100) and then $2 \mathrm{~h}$ incubation with biotinylated secondary goat anti-rabbit immunoglobulin antibody (1:100 Jackson laboratory). Sections were dehydrated in graded alcohol and xylene and mounted with Depex (VWR)

\section{Statistical Methods}

MRS: All analyses were performed using the SAS JMP ${ }^{\circ}$ v11.0.0 software. A statistical model was fitted to the ratios NTP/epp, PCr/Pi and Lac/NAA. An analysis of variance (ANOVA) model was fitted and the differences in the means on the log scale for the three treatment groups $(H T+V, H T+M e l-5$, $\mathrm{HT}+\mathrm{Mel}-15)$ were estimated from the model at each time point with $95 \%$ confidence intervals $(\mathrm{Cl})$ for the differences. The differences in treatment group means are shown graphically using least square mean plots and standard error of the mean (SEM) error bars.

Amplitude intergrateded EEG (aEEG): Following the baseline scoring, scores were obtained hourly until $48 \mathrm{~h}$ after HI. Each subject's scores were averaged over 0-6h, 7-12h, 13-18h, 19-24h, 25-30h, 31-36h, 37-42h and an ANOVA model fitted to the mean scores. The differences in the means 
between the treatment groups were estimated from the model at each of the timepoints with $95 \% \mathrm{Cl}$ for the differences.

TUNEL: An ANOVA model was fitted to the mean counts to give an estimate of the expected counts per $\mathrm{mm}^{2}$. The overall difference between the means for the treatment groups, and treatment differences across regions are presented with 95\% Cls and graphically using 95\% LSD error bars.

Iba-1, GFAP and CC3: An ANOVA model was fitted to the mean counts (using log transformed data for the Iba-1 and GFAP outcomes to satisfy normality assumptions), to investigate the effect of $\mathrm{HT}+\mathrm{Mel}-5$ and $\mathrm{HT}+\mathrm{Mel}-15$ compared to $\mathrm{HT}+\mathrm{V}$ in the sensorimotor and cingulate cortex (areas where TUNEL positive cells were most affected by Mel-15). 


\section{RESULTS}

Forty-eight piglets were studied. Five piglets were excluded prior to $\mathrm{HI}$ as they were in poor condition on baseline studies before $\mathrm{HI}$ ( 3 were pyrexial, one had high cerebral lactate/NAA and one had a flat EEG). Thirteen piglets were excluded just after cerebral $\mathrm{HI}$ due to no or poor NTP/epp recovery ( $<70 \%$ of baseline suggesting very severe insult). Thirty piglets were eligible for inclusion in the study and randomized after $\mathrm{HI}$. There were 13 animals in $\mathrm{HT}+\mathrm{V}$ group, 4 animals in the HT+Mel-5 group and 13 animals in the HT+Mel-15 group. The interim analysis (after 20 piglets) suggested futility in continuing the $5 \mathrm{mg} / \mathrm{kg}$ melatonin group and this group was discontinued. The same randomization schedule was used as prior to the interim analysis, with the HT+Mel-5 group excluded.

\section{Physiological data and insult severity}

There were no significant intergroup differences between groups in bodyweight, postnatal age and baseline physiological measures (Table 1). There was no difference in the $H I$ insult severity between groups (Table 1). There was no difference for volume replacement and inotrope use following $\mathrm{HI}$ between groups (Table 2).

\subsection{T MRS}

The least squares mean plots and SEM bars for the NTP/epp, PCr/Pi and Lac/NAA (on log 10 scale) in thalamus and white matter are shown in Figure 3. Comparing $\mathrm{HT}+\mathrm{V}$ with $\mathrm{HT}+\mathrm{Mel}-5$ and HT+Mel-15 groups, NTP/epp was higher in the HT+Mel-15 group at $24 \mathrm{~h}(p=0.038)$ but not at $48 \mathrm{~h}$. There was no difference in PCr/Pi at any time point. There was no difference for Lac/NAA in white or grey matter at 24 and $48 \mathrm{~h}$ between groups.

\section{aEEG}

There was no difference in the group mean hourly aEEG scores between groups at any timepoint (Figure 4). Three piglets had electrographic seizures, 2 in the $H T+V$ group (one treated with phenobarbitone $20 \mathrm{mg} / \mathrm{kg}$ at $14 \mathrm{~h}$, one treated with phenobarbitone $20 \mathrm{mg} / \mathrm{kg}$ and $10 \mathrm{mg} / \mathrm{kg}$ at $9 \mathrm{~h}$ and $12 \mathrm{~h}$ respectively) and one in the $\mathrm{HT}+\mathrm{Mel}-5$ group (treated with phenobarbitone $20 \mathrm{mg} / \mathrm{kg}$ and $10 \mathrm{mg} / \mathrm{kg}$ at $13 \mathrm{~h}$ and $17 \mathrm{~h}$ respectively). No piglets in the $\mathrm{HT}+\mathrm{Mel}-15$ group had electrographic seizures.

\section{TUNEL}

The estimated mean TUNEL cells $/ \mathrm{mm}^{2}$ for the treatment groups are shown in Table 3 and Figure 5. TUNEL positive cells were counted at 2 brain levels (Figure 2), 8 regions, 3 fields per region. Over all brain regions, there was a trend towards lower TUNEL positive cells in the HT+Mel-15 versus the $H T+V$ treatment group $(p=0.069)$ with the estimated overall TUNEL positive cells $/ \mathrm{mm}^{2}$ 42.1 points lower $(95 \% \mathrm{Cl}-3.3$ to 87.5$)$ in the $\mathrm{HT}+\mathrm{Mel}-15$ group versus $\mathrm{HT}+\mathrm{V}$ alone. In the 
sensorimotor cortex, there was a significantly lower cell death in $\mathrm{HT}+\mathrm{Mel}-15$ versus $\mathrm{HT}+\mathrm{V}$ with the estimated TUNEL positive cells per $\mathrm{mm}^{2} 195.1$ points lower $(95 \% \mathrm{Cl} 67.1$ to $323.1 ; \mathrm{p}=0.003)$. There was a trend towards lower cell death in the sensorimotor cortex in $\mathrm{HT}+\mathrm{Mel}-15$ versus $\mathrm{HT}+\mathrm{Mel}-5$ with the estimated TUNEL positive cells $/ \mathrm{mm}^{2} 172.8$ points lower $(95 \% \mathrm{Cl}-8.3$ to $353.8 ; \mathrm{p}=0.061)$.

\section{Iba1, GFAP and Cleaved caspase 3 (CC3) in the sensorimotor and cingulate cortex}

There were no differences between groups in the cingulate and sensorimotor cortex for Iba-1, GFAP and CC3 (Figure 6).

\section{Pharmacokinetics}

Basal mean $( \pm S D)$ plasma endogenous melatonin levels were detectable in the $H T+V$ group $\left(C_{\max }\right.$ $0.0014 \pm 0.0012 \mathrm{mg} / \mathrm{L}$ and $\mathrm{AUC}_{\text {last }} 0.015 \pm 0.012 \mathrm{mg}{ }^{\star} \mathrm{h} / \mathrm{L}$ ). Mean ( $\pm \mathrm{SD}$ ) plasma melatonin levels in the $\mathrm{HT}+$ Mel-5 group were $\sim 10^{3}$-fold higher $\left(\mathrm{C}_{\max } 3.97 \pm 1.53 \mathrm{mg} / \mathrm{L}\right.$ and $\left.\mathrm{AUC}_{\text {last }} 136 \pm 61 \mathrm{mg}^{*} \mathrm{~h} / \mathrm{L}\right)$. Mean $( \pm S D)$ plasma melatonin levels in the $H T+M e l-15$ group were $\sim 10^{4}$-fold higher $\left(\mathrm{C}_{\max } 16.8 \pm\right.$ $8.3 \mathrm{mg} / \mathrm{L}$ and $\mathrm{AUC}_{\text {last }} 555 \pm 266 \mathrm{mg}{ }^{*} \mathrm{~h} / \mathrm{L}$ ). The $\mathrm{HT}+$ Mel-15 group but not the HT+Mel-5 group had plasma levels comparable with those associated with a neuroprotective effect in our previous study using the ethanol-based melatonin formulation (Robertson et al., 2013). PK modelling suggested that a $2 \mathrm{~h}$ i.v. infusion of melatonin, started at $1 \mathrm{~h}$ after $\mathrm{HI}$, would result in putative therapeutic plasma concentrations by $3 \mathrm{~h}$ (compared to $8 \mathrm{~h}$ in our current study) (Figure 7). CSF melatonin levels at $48 \mathrm{~h}$ in the $\mathrm{HT}+\mathrm{V}$ group were low (ca.0.0001mg/L); in the $\mathrm{HT}+\mathrm{Mel}-15$ group CSF levels were $3.3 \pm 1.3$ $\mathrm{mg} / \mathrm{L}$. Importantly, the mean CSF/plasma melatonin concentration ratio (calculated at $48 \mathrm{~h}$ ) of 0.5 (range $0.3-1.0$ ) in the $\mathrm{HT}+\mathrm{Mel}-15$ group demonstrated adequate CNS penetration. 


\section{DISCUSSION}

Compared to cooling, the current standard therapy for babies with NE, there was a localized reduction in brain cell death in the sensorimotor cortex with the combination of cooling and a $15 \mathrm{mg} / \mathrm{kg}$ proprietary intravenous melatonin formulation (PCT/EP2018/056423) given at $2 \mathrm{~h}$ and $26 \mathrm{~h}$ after cerebral $\mathrm{HI}$ in a piglet model of NE. In the sensorimotor cortex, there was a significantly lower cell death in $\mathrm{HT}+\mathrm{Mel}-15$ versus $\mathrm{HT}+\mathrm{V}$ with the estimated TUNEL positive cells $/ \mathrm{mm}^{2} 195.1$ points lower $(p=0.003)$. With this dose regimen in the $\mathrm{HT}+\mathrm{Mel}-15$ group, plasma melatonin levels were $\sim 10^{4}$ higher at the end of the infusion ( $8 \mathrm{~h}$ after $\mathrm{HI}$ ) than endogenous baseline levels, remaining in this range throughout the study. In the $\mathrm{HT}+\mathrm{Mel}-5$ group, plasma melatonin levels were $10^{3}$ higher at the end of the infusion than endogenous baseline levels and did not reach previously proposed therapeutic range (Carloni et al., 2018 ; Robertson et al., 2013) at 8h or at any time after HI. The lower dose of melatonin (5mg/kg at 2 and $26 \mathrm{~h}$ ), although tested in a limited number of animals, did not show reduced TUNEL positive cells compared to cooling alone (estimated TUNEL positive cells $/ \mathrm{mm}^{2} 22.3$ points lower $(p=0.808$ ) in sensorimotor cortex), suggesting that higher plasma levels of melatonin are required for neuroprotection after cerebral $\mathrm{HI}$, in accordance with in vitro data (Carloni et al., 2018 ; Skaper et al., 1998)

It is unclear why protection was only observed in the sensorimotor cortex with $\mathrm{HT}+\mathrm{Mel}-15$ at $2 \mathrm{~h}$ and $26 \mathrm{~h}$ combined with cooling from 2-26h. The sensorimotor cortex was the area of maximal injury in this study; melatonin targeted this area, reducing TUNEL positive cells but not affecting microglial activation or astrogliosis. Such localized protection is unlikely to be related to vascular factors as melatonin is known to be highly brain penetrant (Paradies et al., 2010) and, indeed, was found in the CSF at concentrations comparable to plasma. Localized protection of the sensorimotor cortex combined with hypothermic protection, might lead to improved motor function which might be detectable at 18 months to 2 years in survivors of NE. In our previous study where melatonin was given at 10 mins after $\mathrm{HI}$, protection was seen across both central deep grey and white matter areas with severe injury (Robertson et al., 2013). It is likely that the earlier administration of melatonin in this study was an important factor in the widespread protection (Robertson et al., 2013). Our data suggest that the time window for intervention with melatonin, as an adjunct therapy with cooling, is narrow, and should be taken into consideration in designing future clinical studies.

Melatonin is likely to be most effective early after $\mathrm{HI}$ through its diverse anti-oxidative mechanisms preventing free radical-induced oxidative damage to the electron transport chain and mitochondrial DNA (Reiter et al., 2016). Melatonin and its metabolites work as potent free radical scavengers, modulating the anti-oxidant capacity by enhancing anti-oxidant enzyme expression and activity (Galano et al., 2011; Galano et al., 2013). Melatonin also protects the integrity of the electron transport chain and increases the activity of complex I and IV so maintaining the mitochondrial energy production. Melatonin thus maintains glutathione homeostasis in the mitochondria and 
increases ATP production (Leon et al., 2004). Melatonin subsequently prevents apoptosis both by directly stabilizing and preventing nitro-oxidative damage to membrane lipids, and by inhibiting proapoptotic proteins such as BAX; these actions prevent leakage of cytochrome $c$ and propagation of the intrinsic apoptotic cascade. The newborn infant is at heightened risk for free radical production and injury from oxidative stress. Birth provides a hyperoxic challenge with transition from a low to high oxygen environment - this is amplified in the already hypoxic neonate who is then often resuscitated with supplemental oxygen (Gitto et al., 2013).

There was no difference in MRS at 48h; the MRS biomarkers measured in this study are known to correlate with injury severity after $\mathrm{HI}$ in the piglet (Lorek et al., 1994; Penrice et al., 1997) and outcome in infants with NE (Mitra et al., 2018). Higher ATP on ${ }^{31} \mathrm{P}$ MRS in infants with NE is associated with better long-term outcome in clinical studies (Azzopardi et al., 1989). We saw higher levels of ATP with $\mathrm{HT}+\mathrm{Mel}-15$ compared to $\mathrm{HT}+\mathrm{V}$ at $24 \mathrm{~h}$ but not $48 \mathrm{~h}$, this may relate to fewer subjects being studied at $48 \mathrm{~h}$. The ${ }^{31} \mathrm{P}$ MRS voxel includes brain tissue in deep grey and white matter, but does not include the cortical regions; this may account for the absence of a difference in ${ }^{31} \mathrm{P}$ MRS. High levels of thalamic lactate/NAA on MRS in neonates in the first month after birth are predictive of a poor 12-18 month neurodevelopmental outcome(Mitra et al., 2018); we saw no difference in Lac/NAA on white or grey matter MRS with $\mathrm{HT}+\mathrm{Mel}-15$ and $\mathrm{HT}+\mathrm{Mel}-5$ compared to $H T+V$. The localized protection seen in the sensorimotor cortex may account for the absence of a difference between groups as the ${ }^{1} \mathrm{H}$ MRS voxels sample the deep grey and white matter only. The amplitude integrated EEG (aEEG) background voltage and rate of aEEG recovery after $\mathrm{HI}$ are also predictive of neurodevelopmental outcome even in babies undergoing $\mathrm{HT}$, with a positive predictive value of an abnormal background pattern of 0.82 at $48 \mathrm{~h}$ (Csekő et al., 2013). aEEG reflects brain electrical activity across all cortical brain regions; we did not observe a difference between groups despite the protection seen in the sensorimotor cortex. It is likely that aEEG background activity was weighted by all cortical areas and not able to detect localized sensorimotor cortex protection.

In this current study, cooling from $2-26 \mathrm{~h}$ with melatonin $(5 \mathrm{mg} / \mathrm{kg}$ or $15 \mathrm{mg} / \mathrm{kg}$ intravenous infusions over $6 \mathrm{~h}$ ) started $2 \mathrm{~h}$ after $\mathrm{HI}$ and repeated at $26 \mathrm{~h}$ after $\mathrm{HI}$, was well tolerated and did not lead to any acute or persisting changes in cardiovascular status or mean blood pressure. This is consistent with previous reports of physiological stability of melatonin in newborns even in high doses (Fulia et al., 2005; Gitto et al., 2001; Gitto et al., 2004a). No study of antenatal or postnatal melatonin treatment has shown any serious side effects (Buscemi et al., 2006; Jahnke et al., 1999). Fulia et al (Fulia et al., 2005) treated asphyxiated term neonates within $6 \mathrm{~h}$ of birth with enteral melatonin at a total dose of $27 \mathrm{mg} / \mathrm{kg}$ over $14 \mathrm{~h}$ which resulted in a reduction in blood markers of lipid peroxidation and nitric oxide (NO) synthesis. Aly et al (Aly et al., 2015) administered enteral melatonin as an adjunct to HT in term NE with a total $50 \mathrm{mg} / \mathrm{kg}$ dose over 5 days, commenced within $6 \mathrm{~h}$. Infants treated with melatonin had reduced plasma levels of $\mathrm{NO}$ and plasma superoxide dismutase after 5 days; there 
was also reduced white matter injury on MR, reduced seizure activity on EEG at 2 weeks and increased survival free of disability at 6 months compared with infants treated with HT. Both these studies used the enteral route for melatonin, either dissolved in ethanol (Fulia et al., 2005) or water (Aly et al., 2015). Aly et al demonstrated only a modest doubling of plasma melatonin levels from baseline to day 5 with $10 \mathrm{mg} / \mathrm{kg} /$ day enteral melatonin $(21 \pm 2.4$ to $42.7 \pm 5.1 \mathrm{pg} / \mathrm{ml} \quad(p<0.001)$, suggesting that the intravenous route of administration is much more effective in elevating plasma concentrations. Interestingly the HT group (without enteral melatonin) also showed an increase in in plasma melatonin from baseline to day $5(20.6 \pm 2.5$ to $32.1 \pm 3.5 \mathrm{pg} / \mathrm{ml}, \mathrm{p}<0.001)$, confirming an endogenous melatonin response previously seen in brain injury (Seifman et al., 2008).

In our study, in the HT+Mel-15 group, plasma melatonin levels increased from $0.0014 \pm 0.0012$ $\mathrm{mg} / \mathrm{L}$ at baseline to $16.8 \pm 8.3 \mathrm{mg} / \mathrm{L}$ at $8 \mathrm{~h}$ after $\mathrm{HI}$ - an increase of $\sim 10^{4}$. In vitro studies using organotypical hippocampal brain slices and ischemia simulated by oxygen and glucose deprivation, suggest that melatonin reduces cell death in a concentration-dependent manner (1-100 uM) with an EC50 of about $25 \mu \mathrm{M}$ (equivalent to $5.8 \mathrm{mg} / \mathrm{L}$ ) (Carloni et al., 2018 ). Extrapolating from this study (Carloni et al., 2018 ) and our previous piglet study (Robertson et al., 2013), it is likely that plasma melatonin levels of $8-32 \mathrm{mg} / \mathrm{L}$ are necessary for maximal neuroprotection after acute $\mathrm{HI}$ in the term brain and that the earlier attainment of therapeutic levels after $\mathrm{HI}$ maximize protection. In a fetal sheep model of preterm $\mathrm{HI}$, a continuous melatonin infusion from $2-26 \mathrm{~h}(0.2 \mathrm{mg}$ intravenous melatonin bolus followed by $0.1 \mathrm{mg} / \mathrm{h}$ for the next $24 \mathrm{~h}$ with ethanol excipient) led to a 70 -fold increase in plasma levels at $10 \mathrm{~h}$ compared to baseline (pre-melatonin infusion values; $10.1 \pm 4.4$ $\mathrm{pg} / \mathrm{ml}$, peak levels $1717 \pm 46 \mathrm{pg} / \mathrm{ml}$ ) (Yawno et al., 2017). Although white matter protection was observed, the influence of ethanol was unclear (Yawno et al., 2017). Recently a term asphyxia sheep model with $60 \mathrm{mg}$ melatonin started at 30 mins after $\mathrm{HI}$ either intravenously or as a transdermal patch was protective (Aridas et al., 2018). The intravenous formulation used ethanol as an excipient; melatonin levels increased 600 fold with a $60 \mathrm{mg}$ dose given over $24 \mathrm{~h}$. Although plasma levels were considerably lower than the putative target therapeutic levels in our piglet study, protection was observed. The contribution of ethanol to protection in the intravenous group is unclear however (Aridas et al., 2018).

It is possible that the ethanol, previously used at sub-toxic doses as an excipient to dissolve melatonin, influenced brain protection in our perinatal asphyxia piglet model (Robertson et al., 2013). A study in fetal sheep with low-dose melatonin $(0.1 \mathrm{mg} / \mathrm{kg}$ over $6 \mathrm{~h})$ showed partial protection confounded by the ethanol used to dissolve melatonin (Drury et al., 2014). Other studies (Miller et al., 2005; Welin et al., 2007; Yawno et al., 2017) have not examined specific effects of ethanol when used as an excipient with melatonin. This is an important issue as neuroprotection has been observed in experimental adult models of stroke (Aronowski et al., 2003; Wang et al., 2012) with ethanol doses of 1.0 to $1.5 \mathrm{~g} / \mathrm{kg}$, which produce blood levels (89 mg/dL) within the legally 
intoxicated range (80-100 g/dL), within $4 \mathrm{~h}$ of middle cerebral artery occlusion (Wang et al., 2012). Possible mechanisms of protection from acute low dose ethanol include increased HIF-1 $\alpha$ expression, however given the unknown risks associated with ethanol exposure in babies (Boschen and Klintsova, 2017; Klintsova et al., 2007), it is likely that a melatonin formulation free of ethanol will be needed to comply with safety regulations for clinical trials.

There are some limitations of our study. The delay of $8 \mathrm{~h}$ for the attainment of $\mathrm{C}_{\max }$ due to the slow infusion protocol used in this study may have reduced the neuroprotective effect of melatonin; the importance of early intervention has been seen with HT (Thoresen et al., 2013) and in the recent early phase clinical trial of xenon-augmented hypothermia in NE where xenon given at $\sim 10 \mathrm{~h}$ after birth had no benefit (Azzopardi et al., 2016). Pharmacokinetic modelling suggests that $18 \mathrm{mg} / \mathrm{kg}$ melatonin started at $1 \mathrm{~h}$ after $\mathrm{HI}$ and given over $2 \mathrm{~h}$ would achieve levels within the therapeutic range by $3 \mathrm{~h}$; this protocol needs to be assessed in future safety and efficacy studies. The $15 \mathrm{mg} / \mathrm{kg}$ dose was the primary target in this study based on previous studies (Robertson et al., 2013); fewer piglets were studied in the $5 \mathrm{mg} / \mathrm{kg}$ group than the $15 \mathrm{mg} / \mathrm{kg}$ group and it is possible that a small effect was missed. The $5 \mathrm{mg} / \mathrm{kg}$ group showed higher blood lactate at baseline and at $12 \mathrm{~h} \mathrm{CO}_{2}$ was increased compared to the other groups; the small group size may have influenced these values. No other differences were seen in any other parameter over the $48 \mathrm{~h}$ study. There are some important strengths of this study: (i) a standard piglet hypothermia protocol was used which is known to be protective in previous studies; (ii) the comparison of doses was based on melatonin plasma levels and not just on nominal dose; (iii) a dose response was evaluated; (iv) the insult severity was the same between groups and those piglets with severe or mild injury were excluded based on pre-defined criteria (<70\% NTP/epp recovery) on ${ }^{31} \mathrm{P} M R S$; (iv) there was delay of $2 \mathrm{~h}$ in starting HT and melatonin reflecting the time of intervention due to the need of clinical assessment of a baby with NE (v) to avoid potential confounding effects, ethanol, an excipient frequently utilized to dissolve melatonin, was not utilized in this study.

We saw no effect of melatonin on brain microglial activation in this study. Melatonin is known to enhance the immune response through augmenting T-helper response (Brzezinski, 1997), reducing production of pro-inflammatory cytokines and reducing polymorphonuclear leukocyte recruitment (Gitto et al., 2013; Lowes et al., 2013). Melatonin can also effectively modulate phagocytosis and expression of proinflammatory mediators in activated microglia (Lowes et al., 2013). Earlier attainment of therapeutic melatonin levels may be important for this effect; we previously observed attenuation of microglial activation and modulated microglial phenotype with melatonin started 10 mins after HI (Robertson et al., 2013). Similarly, we saw no effect of melatonin on cleaved caspase 3 (CC3), usually associated with apoptosis. We have previously observed this disconnect between TUNEL positive cells and CC3 in our 48h model, which may not allow sufficient time for apoptotic 
cell death to fully evolve. No effect on astrogliosis was seen, a finding in accordance with our previous study (Robertson et al., 2013).

In summary, compared to cooling alone, brain cell death was reduced in the sensorimotor cortex with cooling and $15 \mathrm{mg} / \mathrm{kg}$ proprietary intravenous melatonin formulation given $2 \mathrm{~h}$ and $26 \mathrm{~h}$ after cerebral $\mathrm{HI}$ in a piglet model of NE. Plasma melatonin levels increased $\sim 10^{4}$ by $8 \mathrm{~h}$ after $\mathrm{HI}$ with $15 \mathrm{mg} / \mathrm{kg}$ intravenous proprietary melatonin formulation, reaching the putative target therapeutic range at $8 \mathrm{~h}$ and remaining at this level for $48 \mathrm{~h}$. A lower dose of melatonin ( $5 \mathrm{mg} / \mathrm{kg}$ at 2 and $26 \mathrm{~h}$ ) did not reduce TUNEL positive cells in the sensorimotor cortex compared to cooling alone; melatonin levels did not reach the putative therapeutic range with this dose. These data suggest that brain protection after cerebral $\mathrm{HI}$ is dependent on plasma melatonin levels. Melatonin was well tolerated and did not lead to any detectable physiological or biochemical change. The earlier attainment of target plasma melatonin levels may target reperfusion-related oxidative stress, mitochondrial dysfunction and microglia activation and may further augment neuroprotection. For future studies, a similar dose of melatonin given intravenously at $1 \mathrm{~h}$ after $\mathrm{HI}$ with a faster infusion rate is likely to reach putative therapeutic concentrations by $2-3 \mathrm{~h}$ (compared to $8 \mathrm{~h}$ in our current study). Further pre-clinical studies are needed to define the optimal dose regimen of melatonin as an adjunct to HT in NE. 
Funding: The study was funded by Chiesi Farmaceutici S.p.A. (research collaboration agreement with UCL) and supported by the National Institute for Health Research University College London Hospitals Biomedical Research Centre. 


\section{References}

Alonso-Alconada, D., et al., 2015. Brain cell death is reduced with cooling by $3.5^{\circ} \mathrm{C}$ to $5^{\circ} \mathrm{C}$ but increased with cooling by $8.5^{\circ} \mathrm{C}$ in a piglet asphyxia model. Stroke. $46,275-8$.

Aly, H., et al., 2015. Melatonin use for neuroprotection in perinatal asphyxia: a randomized controlled pilot study. J Perinatol. 35, 186-91.

Aridas, J., et al., 2018. Systemic and transdermal melatonin administration prevents neuropathology in response to perinatal asphyxia in newborn lambs. J Pineal Res. doi: 10.1111/jpi.12479. [Epub ahead of print].

Aronowski, J., et al., 2003. Ethanol plus caffeine (caffeinol) for treatment of ischemic stroke: preclinical experience. Stroke. 34, 1246-51.

Azzopardi, D., et al., 2016. Moderate hypothermia within $6 \mathrm{~h}$ of birth plus inhaled xenon versus moderate hypothermia alone after birth asphyxia (TOBY-Xe): a proof-of-concept, openlabel, randomized controlled trial. Lancet Neurol. 15, 145-153.

Azzopardi, D., et al., 1989. Prognosis of newborn infants with hypoxic-ischemic brain injury assessed by phosphorus magnetic resonance spectroscopy. Pediatr Res. 25, 445-51.

Boschen, K., Klintsova, A., 2017. Neurotrophins in the brain:interaction with alcohol exposure during development. . Vitamin Horm. 104, 197-242.

Brzezinski, A., 1997. Melatonin in humans. N Engl J Med. 336, 186-95.

Buscemi, N., et al., 2006. Efficacy and safety of exogenous melatonin for secondary sleep disorders and sleep disorders accompanying sleep restriction: meta-analysis. BMJ. 332, 385-93.

Carloni, S., et al., 2018 Melatonin acts in synergy with hypothermia to reduce oxygen-glucose deprivation (OGD) in rat hippocampus organotypic slice cultures. Neonatology. in press.

Csekő, A., et al., 2013. Accuracy of amplitude-integrated electroencephalography in the prediction of neurodevelopmental outcome in asphyxiated infants receiving hypothermia treatment. Acta Paediatr. 102, 707-11.

Drury, P., et al., 2014. Partial neural protection with prophylactic low-dose melatonin after asphyxia in preterm fetal sheep. J Cereb Blood Flow Metab. 34, 126-35.

Edwards, A., et al., 2010. Neurological outcomes at 18 months of age after moderate hypothermia for perinatal hypoxic ischaemic encephalopathy: synthesis and metaanalysis of trial data. BMJ. 340, C363 doi: 10.1136/bmj.c363.

Faulkner, S., et al., 2011. Xenon augmented hypothermia reduces early lactate/NAA and cell death in Perinatal Asphyxia. Ann Neurol. 70, 133-50.

Fraser, S., et al., 1983. Direct radioimmunoassay and gas chromatography-mass spectrometry compared for determination of melatonin in plasma. Clin Chem. 29, 1703-4.

Fulia, F., et al., 2005. Increased levels of malondialdehyde and nitrite/nitrate in the blood of asphyxiated newborns: reduction by melatonin. J Pineal Res. 31, 343-9.

Galano, A., et al., 2011. Melatonin as a natural ally against oxidative stress: a physicochemical examination. J Pineal Res. 51, 1-16.

Galano, A., et al., 2013. On the free radical scavenging activities of melatonin's metabolites, AFMK and AMK. J Pineal Res. 54, 245-57.

Gitto, E., et al., 2001. Effects of melatonin treatment in septic newborns. Pediatr Res. 50, 75660.

Gitto, E., et al., 2013. Protective role of melatonin in neonatal diseases. Oxid Med Cell Longev. 2013, 980374.

Gitto, E., et al., 2004a. Oxidative and inflammatory parameters in respiratory distress syndrome of preterm newborns: beneficial effects of melatonin. Am J Perinatol. 21, 20916. 
Gitto, E., et al., 2004b. Melatonin reduces oxidative stress in surgical neonates. J Pediatr Surg. 39, 184-9.

Hellström-Westas, L., et al., 1995. Predictive value of early continuous amplitude integrated EEG recordings on outcome after severe birth asphyxia in full term infants. Arch Dis Child Fetal Neonatal Ed. 72, F34-8.

Husson, I., et al., 2002. Melatoninergic neuroprotection of the murine periventricular white matter against neonatal excitotoxic challenge. Ann Neurol. 51, 82-92.

Jacobs, S., et al., 2011. Whole-body hypothermia for term and near-term newborns with hypoxic-ischemic encephalopathy: a randomized controlled trial. Arch Pediatr Adolesc Med. 165, 692-700.

Jahnke, G., et al., 1999. Maternal and developmental toxicity evaluation of melatonin administered orally to pregnant Sprague-Dawley rats. Toxicol Sci. 50, 271-9.

Jenkins, D., et al., 2013. Altered circulating leukocytes and their chemokines in a clinical trial of therapeutic hypothermia for neonatal hypoxic ischemic encephalopathy. Pediatr Crit Care Med. 14, 786-95.

Kilic, U., et al., 2005. Signal transduction pathways involved in melatonin-induced neuroprotection after focal cerebral ischemia in mice. J Pineal Res. 38, 67-71.

Klintsova, A., et al., 2007. Persistent impairment of hippocampal neurogenesis in young adult rats following early postnatal alcohol exposure. . Alcohol Clin Exp Res. 31, 2073-82.

Kurinczuk, J., et al., 2010. Epidemiology of neonatal encephalopathy and hypoxic-ischaemic encephalopathy. Early Hum Dev. 86, 329-38.

Leon, J., et al., 2004. Melatonin and mitochondrial function. Life Sci. 75, 765-90.

Liu, L., et al., 2016. Global, regional, and national causes of under-5 mortality in 2000-15: an updated systematic analysis with implications for the Sustainable Development Goals. Lancet. 388, 3027-3035.

Lorek, A., et al., 1994. Delayed ("secondary") cerebral energy failure after acute hypoxiaischemia in the newborn piglet: continuous 48-hour studies by phosphorus magnetic resonance spectroscopy. Pediatr Res. 36, 699-706.

Lowes, D., et al., 2013. Antioxidants that protect mitochondria reduce interleukin- 6 and oxidative stress, improve mitochondrial function, and reduce biochemical markers of organ dysfunction in a rat model of acute sepsis. Br J Anaesth. 110, 472-80.

Luchetti, F., et al., 2010. Melatonin signaling and cell protection function. FASAB J. 24, 3603-24.

Macleod, M., et al., 2005. Systematic review and meta-analysis of the efficacy of melatonin in experimental stroke. J Pineal Res. 2005 Jan;38(1):35-41. 38, 35-41.

Mandel, P., Edel-Harth, S., 1966. Free nucleotides in the rat brain during post-natal development. J Neurochem. 13, 591-5.

Marek, E., Kraft, W., 2014. Ethanol pharmacokinetics in neonates and infants. Curr Ther Res Clin Exp. 76, 90-7.

Miller, S., et al., 2005. Melatonin provides neuroprotection in the late-gestation fetal sheep brain in response to umbilical cord occlusion. Dev Neurosci. 27, 200-10.

Mitra, S., et al., 2018. Proton MRS derived basal ganglia and thalamic Lac+Thr/tNAA at 3T has a high predictive value for motor, cognitive and language outcome in neonatal encephalopathy treated with therapeutic hypothermia. . Radiology (in press).

NPEU, MBRRACE-UK: Mothers and Babies: Reducing Risk from Audits and confidential Enquiries across the UK. https://www.npeu.ox.ac.uk/mbrrace-uk, 2017.

Paradies, G., et al., 2010. Melatonin, cardiolipin and mitochondrial bioenergetics in health and disease. J Pineal Res. 48, 297-310.

Penrice, J., et al., 1997. Proton magnetic resonance spectroscopy of the brain during acute hypoxia-ischemia and delayed cerebral energy failure in the newborn piglet. Pediatr Res. 41, 795-802. 
Reiter, R., et al., 2016. Melatonin as an antioxidant: under promises but over delivers. J Pineal Res. 61, 253-78.

Robertson, N., et al., 2013. Melatonin Augments Hypothermic Neuroprotection in a Perinatal Asphyxia Piglet Model. Brain. 136(Pt 1), 90-105.

Robertson, N., et al., 2012. Which neuroprotective agents are ready for bench to bedside translation in the newborn infant? J Pediatr. 160, 544-552.

Seifman, M., et al., 2008. Endogenous melatonin increases in cerebrospinal fluid of patients after severe traumatic brain injury and correlates with oxidative stress and metabolic disarray. J Cereb Blood Flow Metab. 28, 684-96.

Shankaran, S., et al., 2014. Effect of depth and duration of cooling on deaths in the NICU among neonates with hypoxic ischemic encephalopathy: a randomized clinical trial. JAMA. 312, 2629-39.

Shankaran, S., et al., 2017. Effect of Depth and Duration of Cooling on Death or Disability at Age 18 Months Among Neonates With Hypoxic-Ischemic Encephalopathy: A Randomized Clinical Trial. JAMA. 318, 57-67.

Skaper, S., et al., 1998. Melatonin prevents the delayed death of hippocampal neurons induced by enhanced excitatory neurotransmission and the nitridergic pathway. FASEB J. 12, 725-31.

Su, F., et al., 2017. Low-Dose Ethanol Preconditioning Protects Against Oxygen-Glucose Deprivation/Reoxygenation-Induced Neuronal Injury By Activating Large Conductance, Ca2+-Activated K+ Channels In Vitro. Neuroscience Bulletin. 33, 28-40.

Thoresen, M., et al., 2013. Time is brain: starting therapeutic hypothermia within three hours after birth improves motor outcome in asphyxiated newborns. Neonatology. 104, 22833.

van Rooij, L., et al., 2005. Recovery of amplitude integrated electroencephalographic background patterns within 24 hours of perinatal asphyxia. Arch Dis Child Fetal Neonatal Ed. 90, F243-51.

Vanhamme, L., et al., 1997. Improved method for accurate and efficient quantification of MRS data with use of prior knowledge. J Magn Reson Imaging. 129, 35-43.

Wang, F., et al., 2012. Neuroprotective effect of acute ethanol administration in a rat with transient cerebral ischemia. Stroke. 43, 205-10.

Welin, A., et al., 2007. Melatonin reduces inflammation and cell death in white matter in the mid-gestation fetal sheep following umbilical cord occlusion. Pediatr Res. 61, 153-8.

Whittaker, A., et al., 2009. Toxic additives in medication for preterm infants. Arch Dis Child Fetal Neonatal Ed. 94, F236-40.

Yawno, T., et al., 2017. The Beneficial Effects of Melatonin Administration Following HypoxiaIschemia in Preterm Fetal Sheep. Front Cell Neurosci. 11, 296. 


\section{Figure Legends}

\section{Figure 1.}

Study time line. Following baseline data acquisition and screening for health, piglets underwent cerebral hypoxia-ischemia. Following hypoxia-ischemia and cerebral NTP recovery $>70 \%$, piglets were randomized to (i) Hypothermia $\left(33.5^{\circ} \mathrm{C}\right.$ from $\left.2-26 \mathrm{~h}\right)+$ Vehicle $(H T+V)$; (ii) $H T+5 \mathrm{mg} / \mathrm{kg}$ melatonin (Mel-5) at $2 \mathrm{~h}$ and $26 \mathrm{~h}$ and infused over $6 \mathrm{~h}$; (iii) $\mathrm{HT}+15 \mathrm{mg} / \mathrm{kg}$ melatonin (Mel-15) at $2 \mathrm{~h}$ and $26 \mathrm{~h}$ and infused over $6 \mathrm{~h}$. Piglets were maintained under intensive care for $48 \mathrm{~h}$ following $\mathrm{HI}$. MRS was acquired at baseline, during $\mathrm{HI}$ and 60 mins after resuscitation, at 24 and $48 \mathrm{~h}$. aEEG was acquired at baseline and between MRS studies.

\section{Figure 2.}

The two brain levels ( $A$ and $B$ ) sampled are shown as well as the 8 brain regions assessed for immunohistochemistry (3 fields per region, 2 levels). The red squares represent those areas sampled by MRS and the black squares those regions not sampled by MRS.

\section{Figure 3.}

Magnetic resonance spectroscopy of the brain at baseline, $24 \mathrm{~h}$ and $48 \mathrm{~h}$ after hypoxia ischemia. All groups underwent therapeutic hypothermia (HT) from 2-26h. Least square mean plots with standard error of the mean (SEM) error bars are shown for NTP/epp and PCr/Pi in whole forebrain and Lac/NAA in the white and grey matter for vehicle, Mel-5 and Mel-15 groups. NTP/epp was higher in the HT+Mel-15 group at $24 \mathrm{~h}(p=0.038)$ but not at $48 \mathrm{~h}$. there were no other differences between groups. epp = exchangeable phosphate pool; Lac= lactate; $N A A=N$-acetyl aspartate; $\mathrm{WM}=$ white matter; $\mathrm{HI}=$ hypoxia-ischemia.

\section{Figure 4.}

Amplitude-integrated electroencephalogram (aEEG). Scores were obtained hourly until $48 \mathrm{~h}$ and averaged over 6 hourly periods. An ANOVA model was fitted and the differences in the means between the treatment groups estimated with $95 \%$ Cls for the differences There was no difference in the group mean hourly aEEG scores between groups. Representative aEEG traces for each score are shown in the lower panel.

\section{Figure 5}

Mean TUNEL counts for $\mathrm{HT}+\mathrm{V}, \mathrm{HT}+\mathrm{Mel}-5$ and $\mathrm{HT}+\mathrm{Mel}-15$. Fig $5 \mathrm{~A}$ shows TUNEL counts across 8 different brain regions. There is a significant reduction in TUNEL positive cells in the HT+Mel-15 group compared to $H T+V$ in the sensorimotor cortex $(p=0.003)$. Representative TUNEL sections of the sensorimotor cortex are shown in Fig 5B-D. cCTX = cingulate cortex; $s C T X=$ sensorimotor 
cortex; Hip = hippocampus; pvWM = periventricular white matter; IC = internal capsule; Caud = caudate nucleus; PTMN = putamen; THAL = thalamus.

\section{Figure 6}

Immunohistochemistry in the sensorimotor and cingulate cortex in $\mathrm{HT}+\mathrm{V}, \mathrm{HT}+\mathrm{Mel}-5$ and $\mathrm{HT}+\mathrm{Mel}-$ 15 groups. The top panel shows cleaved caspase 3 (CC3), middle panel IBA- 1 staining and lower panel GFAP. There was no difference in any of the immunohistochemical markers between groups.

\section{Figure 7}

Mean plasma concentrations $( \pm \mathrm{SD}$ ) of the $\mathrm{HT}+\mathrm{Mel}-5$ (red line) and $\mathrm{HT}+\mathrm{Mel}-15$ groups (blue line) compared with the historical data from Robertson et al., 2013 (green line); plasma concentrations of the HT+V group ( $<0.125 \mathrm{mg} / \mathrm{L}$ ) could not be plotted due to the $\mathrm{Y}$ axis scale used. The modelled $\mathrm{PK}$ for $15 \mathrm{mg} / \mathrm{kg}$ over a $2 \mathrm{hr}$-infusion at $1 \mathrm{~h}$ after $\mathrm{HI}$ is shown by dotted orange line. All concentrations are plotted considering the end of $\mathrm{HI}$ as $\mathrm{t}=0$. 
Table 1. Baseline group data and physiological variables throughout the study

\begin{tabular}{|c|c|c|c|c|}
\hline Parameters & $\begin{array}{c}\text { Vehicle } \\
\text { Mean (SD) }\end{array}$ & $\begin{array}{l}5 \mathrm{mg} / \mathrm{kg} / 24 \mathrm{~h} \\
\text { Mean (SD) }\end{array}$ & $\begin{array}{c}15 \mathrm{mg} / \mathrm{kg} / 24 \mathrm{~h} \\
\text { Mean (SD) }\end{array}$ & $\begin{array}{l}\mathbf{P} \\
\text { value }\end{array}$ \\
\hline Body weight (g) & $1916.15 \quad(193.46)$ & $1862.50 \quad(110.87)$ & $1977.69 \quad(120.63)$ & .378 \\
\hline Duration of $\mathrm{HI}(\mathrm{min})$ & $26.31 \quad(4.03)$ & $24.25 \quad(2.22)$ & $26.46 \quad(4.16)$ & .602 \\
\hline $\begin{array}{l}\text { Insult severity (10-2) } \\
\text { measured from acute } \\
\text { energy depletion } \\
\text { (AED) }\end{array}$ & $0.08 \quad(0.04)$ & $0.10 \quad(0.02)$ & $0.08 \quad(0.04)$ & .508 \\
\hline \multicolumn{5}{|l|}{ Heart rate $(\min -1)$} \\
\hline Baseline & $\begin{array}{ll}173.63 & (15.24) \\
\end{array}$ & $171.92 \quad(8.82)$ & $178.45 \quad(20.44)$ & .706 \\
\hline End of insult (time 0 ) & $186.91 \quad(20.27)$ & $180.31 \quad(24.28)$ & $191.60 \quad(32.72)$ & .751 \\
\hline $1-2 \mathrm{~h}$ after time 0 & $177.77 \quad(20.38)$ & $182.88 \quad(35.65)$ & $173.54 \quad(18.09)$ & .732 \\
\hline $2-26 \mathrm{~h}$ after time 0 & $151.85 \quad(22.41)$ & $160.76 \quad(19.85)$ & $153.42 \quad(16.81)$ & .735 \\
\hline $26-48 \mathrm{~h}$ after time 0 & $177.07 \quad(23.2)$ & $155.81 \quad(13.2)$ & $169.64 \quad(12.27)$ & .132 \\
\hline \multicolumn{5}{|l|}{$\begin{array}{l}\text { Mean arterial blood } \\
\text { pressure }(\mathrm{mm} \mathrm{Hg})\end{array}$} \\
\hline Baseline & $47.89 \quad(5.73)$ & $41.58 \quad(1.23)$ & $47.10 \quad(5.54)$ & .129 \\
\hline End of insult (time 0 ) & $43.76 \quad(6.67)$ & $38.06 \quad(5.28)$ & $43.17 \quad(6.61)$ & .310 \\
\hline $1-2 \mathrm{~h}$ after time 0 & $42.73 \quad(7.05)$ & $43.06 \quad(8.82)$ & $44.19 \quad(6.36)$ & .865 \\
\hline $2-26 \mathrm{~h}$ after time 0 & $45.99 \quad(3.77)$ & $42.99 \quad(3.61)$ & $48.23 \quad(6.63)$ & .205 \\
\hline $26-48 \mathrm{~h}$ after time 0 & $50.51 \quad(6.52)$ & $52.93 \quad(7.53)$ & $51.69 \quad(6.48)$ & .799 \\
\hline \multicolumn{5}{|l|}{$\begin{array}{l}\text { Rectal temperature } \\
\left({ }^{\circ} \mathrm{C}\right)\end{array}$} \\
\hline Baseline & $38.23 \quad(0.56)$ & $\begin{array}{ll}38.46 & (0.2) \\
\end{array}$ & $38.29 \quad(0.31)$ & .649 \\
\hline End of insult (time 0 ) & $37.91 \quad(0.41)$ & $38.10 \quad(0.3)$ & $38.17 \quad(0.56)$ & .399 \\
\hline $1-2 \mathrm{~h}$ after time 0 & $37.98 \quad(0.98)$ & $38.29 \quad(0.39)$ & $38.10 \quad(0.79)$ & .802 \\
\hline $2-26 \mathrm{~h}$ after time 0 & $33.71 \quad(0.11)$ & $33.89 \quad(0.18)$ & $33.73 \quad(0.25)$ & .250 \\
\hline $26-48 \mathrm{~h}$ after time 0 & $36.59 \quad(1.01)$ & $37.12 \quad(0.14)$ & $37.05 \quad(0.39)$ & .219 \\
\hline \multicolumn{5}{|l|}{$\mathrm{PaO} 2(\mathrm{kPa})$} \\
\hline Baseline & $16.59 \quad(11.02)$ & $16.05 \quad(5.12)$ & $16.73 \quad(5.7)$ & .990 \\
\hline End of insult (time 0 ) & $11.26 \quad(2.76)$ & $10.93 \quad(2.19)$ & $10.85 \quad(2.27)$ & .910 \\
\hline $12 \mathrm{~h}$ after time 0 & $12.35 \quad(2.93)$ & $10.28 \quad(1.03)$ & $10.66 \quad(3.68)$ & .317 \\
\hline $24 \mathrm{~h}$ after time 0 & $12.28 \quad(2.11)$ & $9.78 \quad(2.74)$ & $14.02 \quad(4.75)$ & .127 \\
\hline $48 \mathrm{~h}$ after time 0 & $13.40 \quad(2.61)$ & $13.00 \quad(0)$ & $\begin{array}{ll}17.47 & (9.09) \\
\end{array}$ & .494 \\
\hline \multicolumn{5}{|l|}{$\mathrm{PaCO} 2(\mathrm{kPa})$} \\
\hline Baseline & $6.55 \quad(3.73)$ & $5.17 \quad(1.13)$ & $5.72 \quad(1.8)$ & .597 \\
\hline End of insult (time 0 ) & $5.04 \quad(1.03)$ & $5.54 \quad(1.28)$ & $4.96 \quad(1.51)$ & .739 \\
\hline $12 \mathrm{~h}$ after time 0 & $4.61 \quad(1.42)$ & $6.60 \quad(1.17)$ & $4.84 \quad(1.05)$ & .029 \\
\hline $24 \mathrm{~h}$ after time 0 & $4.67 \quad(1)$ & $5.08 \quad(1.09)$ & $4.32 \quad(0.51)$ & .239 \\
\hline $48 \mathrm{~h}$ after time 0 & $5.28 \quad(0.62)$ & $4.94 \quad(0)$ & $5.17 \quad(1.18)$ & .944 \\
\hline \multicolumn{5}{|l|}{ Blood pH } \\
\hline Baseline & $\begin{array}{ll}7.41 & (0.17) \\
\end{array}$ & $\begin{array}{ll}7.46 & (0.02) \\
\end{array}$ & $7.47 \quad(0.15)$ & .629 \\
\hline End of insult (time 0 ) & $7.33 \quad(0.08)$ & $7.34 \quad(0.17)$ & $7.34 \quad(0.13)$ & .983 \\
\hline $12 \mathrm{~h}$ after time 0 & $7.51 \quad(0.12)$ & $\begin{array}{ll}7.41 & (0.04) \\
\end{array}$ & $\begin{array}{ll}7.53 & (0.11) \\
\end{array}$ & .187 \\
\hline
\end{tabular}




\begin{tabular}{|c|c|c|c|c|}
\hline $24 \mathrm{~h}$ after time 0 & $7.49 \quad(0.08)$ & $7.50 \quad(0.11)$ & $7.54 \quad(0.07)$ & .406 \\
\hline $48 \mathrm{~h}$ after time 0 & $7.42 \quad(0.04)$ & $7.41 \quad(0)$ & $7.45 \quad(0.09)$ & .714 \\
\hline \multicolumn{5}{|l|}{ Base excess (mmol/l) } \\
\hline Baseline & $4.08 \quad(4.42)$ & $3.50 \quad(5.51)$ & $5.92 \quad(3.48)$ & .420 \\
\hline End of insult (time 0 ) & $-6.00 \quad(5.26)$ & $-4.00 \quad(6.06)$ & $-6.38 \quad(3.75)$ & .692 \\
\hline $12 \mathrm{~h}$ after time 0 & $4.54 \quad(5.86)$ & $5.75 \quad(2.5)$ & $7.31 \quad(3.86)$ & .352 \\
\hline $24 \mathrm{~h}$ after time 0 & $3.33 \quad(4.91)$ & $6.25 \quad(3.2)$ & $5.08 \quad(3.62)$ & .389 \\
\hline $48 \mathrm{~h}$ after time 0 & $1.29 \quad(1.94)$ & $-1.00(0)$ & $3.00 \quad(3.79)$ & .354 \\
\hline \multicolumn{5}{|l|}{ Lactate (mmol/l) } \\
\hline Baseline & $3.59 \quad(2.26)$ & $7.55 \quad(2.04)$ & $4.59 \quad(2.16)$ & .013 \\
\hline End of insult (time 0 ) & $9.19 \quad(2.36)$ & $10.09 \quad(1.22)$ & $9.51 \quad(2.52)$ & .803 \\
\hline $12 \mathrm{~h}$ after time 0 & $3.08 \quad(2.09)$ & $2.03 \quad(0.41)$ & $2.70 \quad(1.13)$ & .485 \\
\hline $24 \mathrm{~h}$ after time 0 & $2.30 \quad(0.83)$ & $1.71 \quad(0.46)$ & $2.27 \quad(0.98)$ & .474 \\
\hline $48 \mathrm{~h}$ after time 0 & $1.48 \quad(0.71)$ & $2.19 \quad(0)$ & $1.23 \quad(0.29)$ & .105 \\
\hline \multicolumn{5}{|l|}{ Glucose (mmol/l) } \\
\hline Baseline & $5.88 \quad(0.98)$ & $6.58 \quad(1.46)$ & $6.02 \quad(1.12)$ & .541 \\
\hline End of insult (time 0 ) & $9.20 \quad(2.29)$ & $9.33 \quad(3.11)$ & $8.55 \quad(1.61)$ & .678 \\
\hline $12 \mathrm{~h}$ after time 0 & $8.65 \quad(3.52)$ & $10.1 \quad(4.1)$ & $8.50 \quad(2.24)$ & .646 \\
\hline $24 \mathrm{~h}$ after time 0 & $\begin{array}{ll}10.83 & (4.17) \\
\end{array}$ & $10.8 \quad(2.59)$ & $9.89 \quad(3.97)$ & .821 \\
\hline $48 \mathrm{~h}$ after time 0 & $5.76 \quad(1.48)$ & $4.9 \quad(0)$ & $5.63 \quad(1.14)$ & .810 \\
\hline
\end{tabular}

Table 1. Time zero was set at the time of reperfusion/resuscitation. Mean \pm standard deviation (SD) values are presented for the three groups; (i) HT+V ( $n=13)$; (ii) HT+Mel-5 ( $n=4)$; (iii) HT+Mel-15 $(n=13)$. Apart from a higher lactate at baseline and higher $\mathrm{CO}_{2}$ at $12 \mathrm{~h}$ in the HT+MEL-5 group, analysis using Mann Whitney test indicated that there was no evidence of a difference between the two groups for any of the outcomes at any of the time-points. Insult severity was estimated by calculating the time integral of the change in NTP/epp during $\mathrm{HI}$ and the first 60 min of resuscitation. 


\begin{tabular}{|l|ccccccc|}
\hline \multicolumn{1}{|c|}{ Infusions } & \multicolumn{2}{|c}{$\begin{array}{c}\text { HT+V } \\
\text { Mean (SD) }\end{array}$} & \multicolumn{2}{c|}{$\begin{array}{c}\text { HT+Mel-5 } \\
\text { Mean (SD) }\end{array}$} & $\begin{array}{c}\text { HT+Mel-15 } \\
\text { Mean (SD) }\end{array}$ & $\begin{array}{l}\text { P } \\
\text { value }\end{array}$ \\
\hline & & & & & & & \\
Dopamine $(\boldsymbol{\mu g} / \mathbf{k g} / \mathbf{m i n})$ & 10.869 & $(5.314)$ & 11.964 & $(5.404)$ & 13.500 & $(3.255)$ & 0.647 \\
Dobutamine $(\boldsymbol{\mu g} / \mathbf{k g} / \mathbf{m i n})$ & 5.24 & $(-4.905)$ & 3.405 & $(5.304)$ & 7.811 & $(1.822)$ & 0.277 \\
Noradrenaline(ng/kg/min) & 9.686 & $(17.142)$ & 7.731 & $(17.122)$ & 2.171 & $(4.342)$ & 0.716 \\
Adrenaline $(\mathbf{n g} / \mathbf{k g} / \mathbf{m i n})$ & 0.753 & $(2.827)$ & 0 & $(0)$ & 0.000 & $(0.000)$ & 0.536 \\
Saline Bolus $(\mathbf{m l} / \mathbf{k g})$ & 0.166 & $(0.123)$ & 0.138 & $(0.068)$ & 0.192 & $(0.077)$ & 0.565 \\
& & & & & & & \\
\hline
\end{tabular}

Table 2. Average total volume replacement and inotrope infusion for the piglets in the $H T+V$, $\mathrm{HT}+\mathrm{Mel}-5$ and $\mathrm{HT}+\mathrm{Mel}-15$ groups during the $48 \mathrm{~h}$ after $\mathrm{HI}$. 


\begin{tabular}{|c|c|c|c|c|c|c|}
\hline Area & Comparison & $\begin{array}{c}\text { Difference in } \\
\text { Mean TUNEL } \\
\text { Count }\end{array}$ & $\begin{array}{c}\text { SE of } \\
\text { Difference }\end{array}$ & $\begin{array}{l}\text { Lower 95\% } \\
\text { C.I. for } \\
\text { Difference }\end{array}$ & $\begin{array}{l}\text { Upper } 95 \% \\
\text { C.I. for } \\
\text { Difference }\end{array}$ & $p$-value \\
\hline \multirow{3}{*}{$\begin{array}{l}\text { Sensorimotor } \\
\text { cortex }\end{array}$} & $\begin{array}{c}\text { HT+V v. } \\
\text { HT+Mel-15 }\end{array}$ & 195.1 & 64.9 & 67.1 & 323.1 & 0.003 \\
\hline & $\begin{array}{c}\text { HT+V v. HT+Mel- } \\
5 \\
\end{array}$ & 22.3 & 91.8 & -158.7 & 203.4 & 0.808 \\
\hline & $\begin{array}{c}\text { HT+Mel-5 v. } \\
\text { HT+Mel-15 }\end{array}$ & 172.8 & 91.8 & -8.3 & 353.8 & 0.061 \\
\hline \multirow{3}{*}{ OVERALL } & $\begin{array}{c}\text { HT+V v. } \\
\text { HT+Mel-15 }\end{array}$ & 42.1 & 23.0 & -3.3 & 87.5 & 0.069 \\
\hline & $\begin{array}{c}\text { HT+V v. } \\
\text { HT+Mel-5 }\end{array}$ & -0.9 & 32.5 & -65.0 & 63.2 & 0.977 \\
\hline & $\begin{array}{c}\text { HT+Mel-5 v. } \\
\text { HT+Mel-15 }\end{array}$ & 43.0 & 32.5 & -21.0 & 107.0 & 0.187 \\
\hline
\end{tabular}

Table 3. Differences between $H T+V, H T+M e l-5$ and $H T+M e l-15$ group TUNEL counts for the sensorimotor cortex and overall (8 brain regions). The other brain regions did not show a significant difference in TUNEL counts. 
PK Bloods: Baseline, before infusion, 1, 3, 5, 12, 18, 24, 25, 27, 30, 36, 42, 48 hours

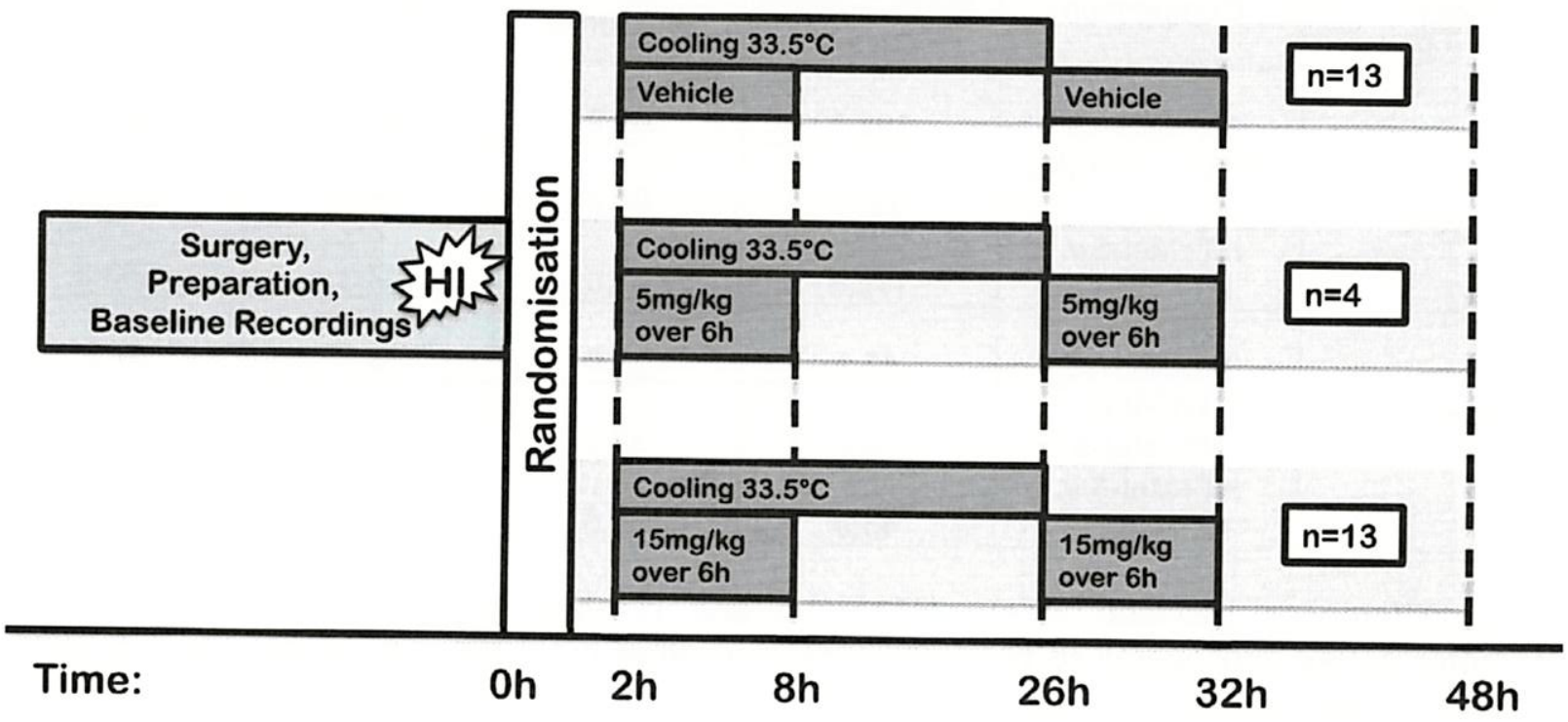

Continuous intensive care monitoring, ventilation and support

\begin{tabular}{|l|l|l|l|l|l}
\hline EEG & MRS & EEG & MRS & EEG & MRS \\
\hline
\end{tabular}




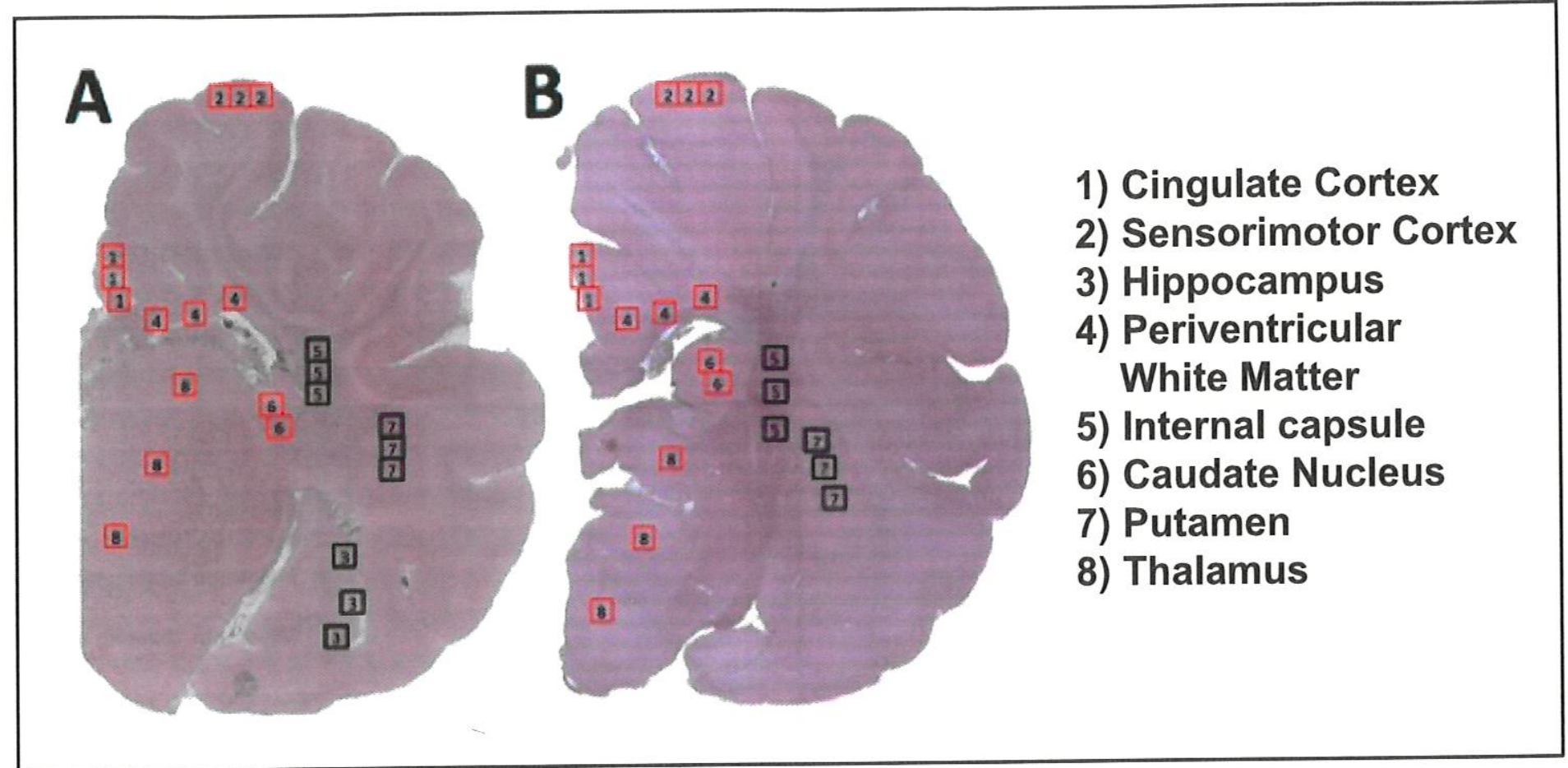


Whole Brain

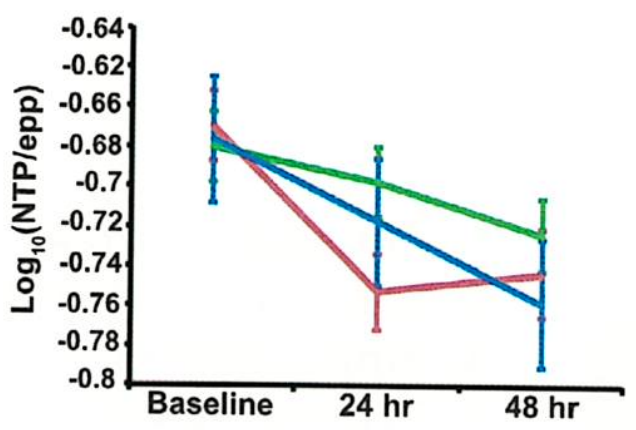

Thalamus

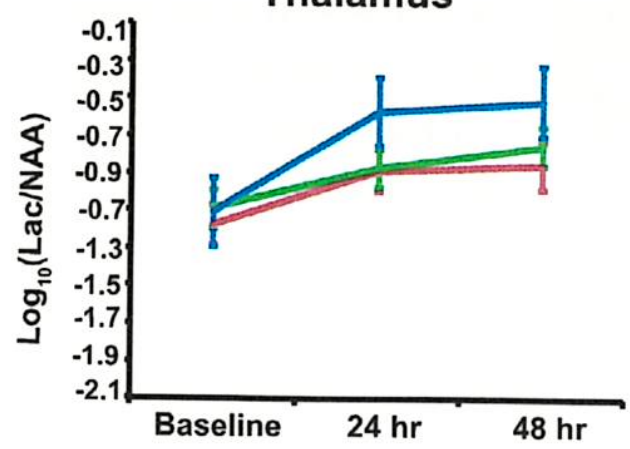

\section{Whole Brain}
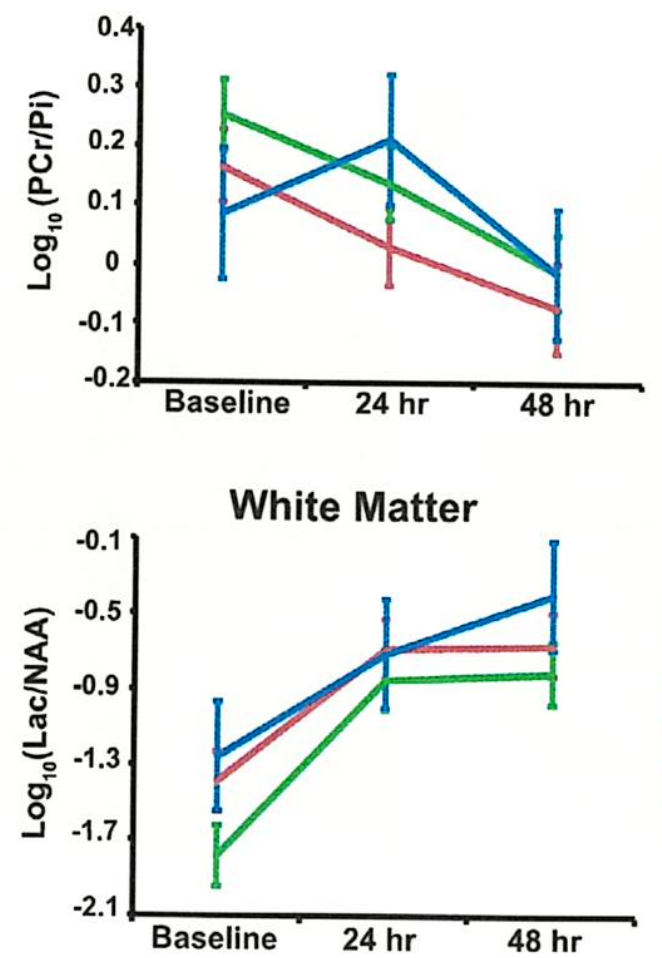

Vehicle

Melatonin $5 \mathrm{mg} / \mathrm{kg}$ over $6 \mathrm{~h}$

Melatonin $15 \mathrm{mg} / \mathrm{kg}$ over $6 \mathrm{~h}$
Whole Brain

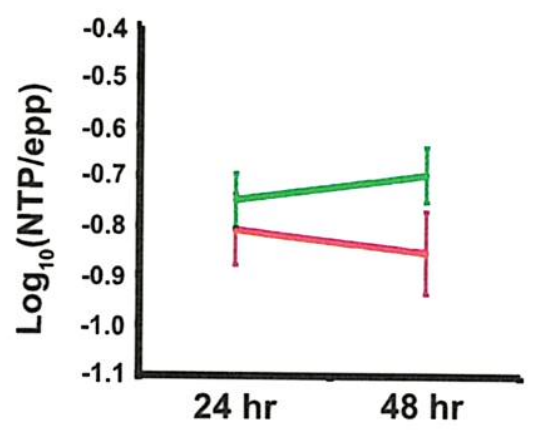

Thalamus

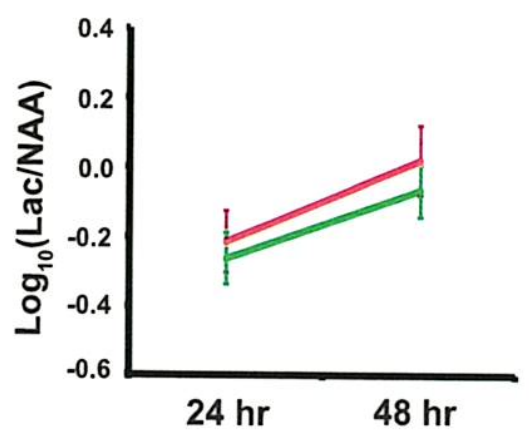

Whole Brain

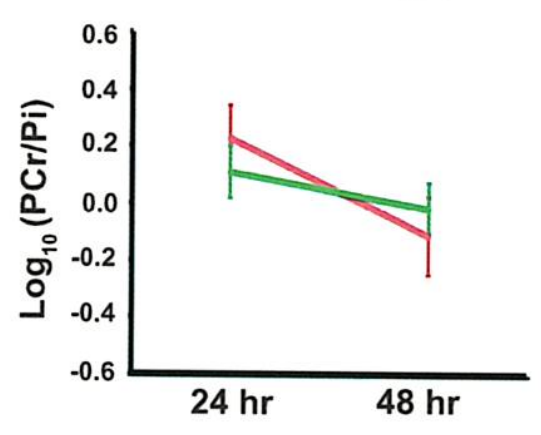

White Matter

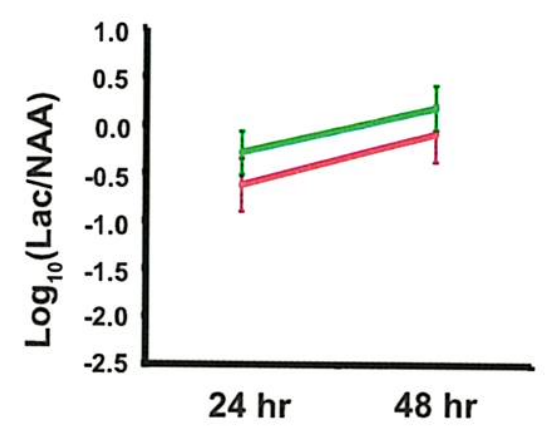

Vehicle

Melatonin $15 \mathrm{mg} / \mathrm{kg}$ over $6 \mathrm{~h}$ 


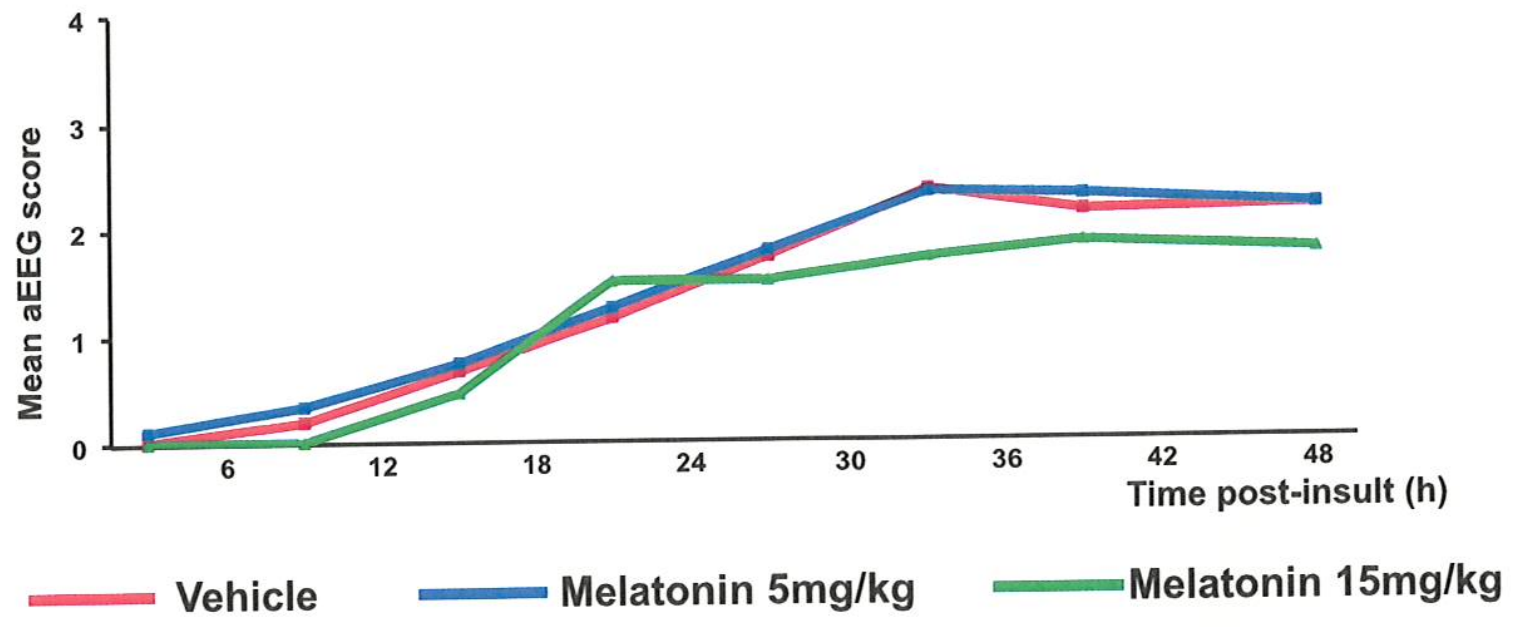

Classification of Amplitude-Integrated EEG

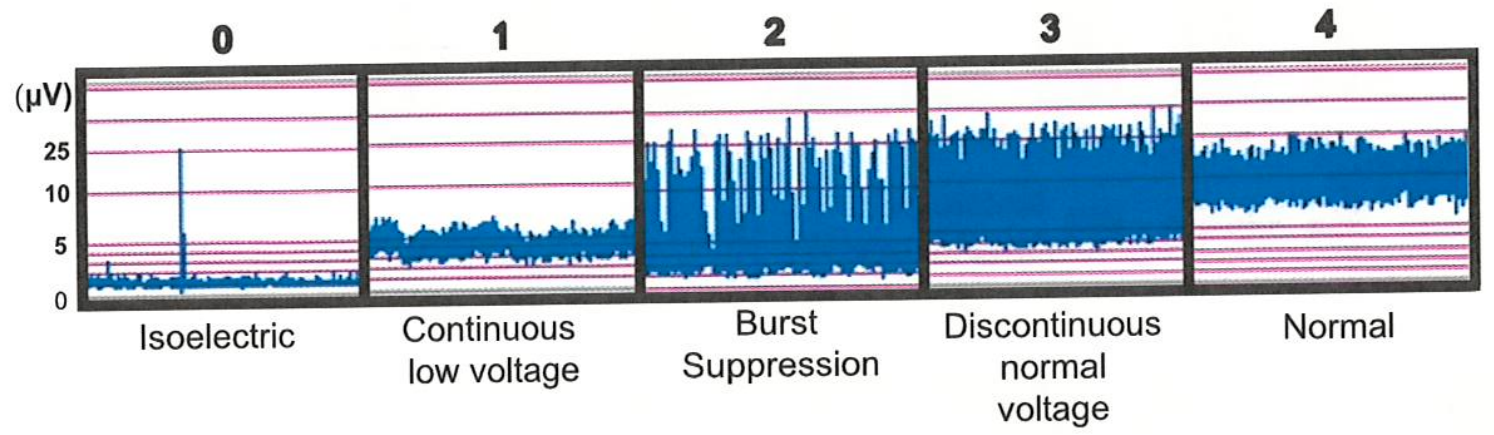




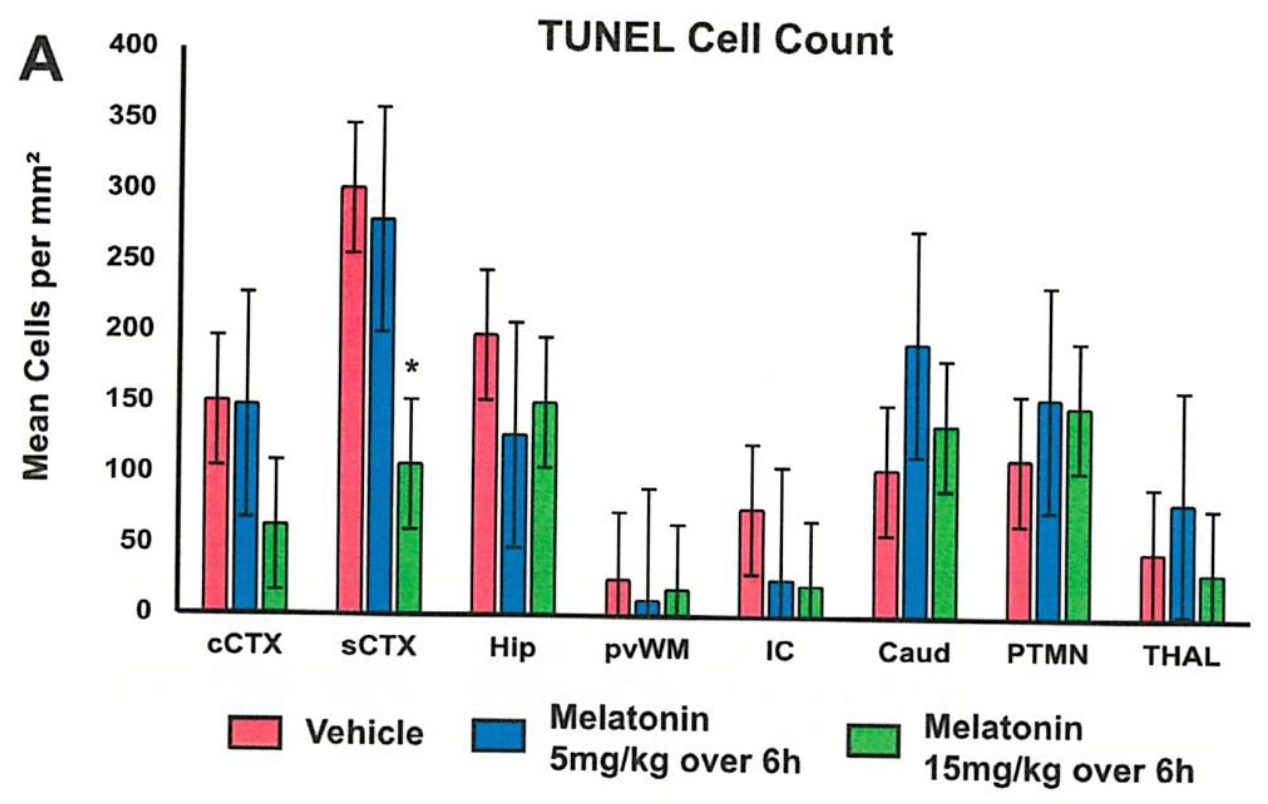

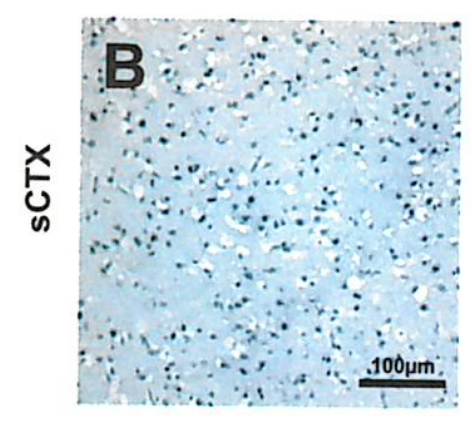

Vehicle

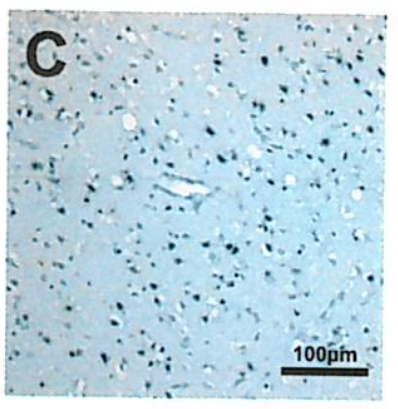

Melatonin $5 \mathrm{mg} / \mathrm{kg}$ over $6 \mathrm{~h}$

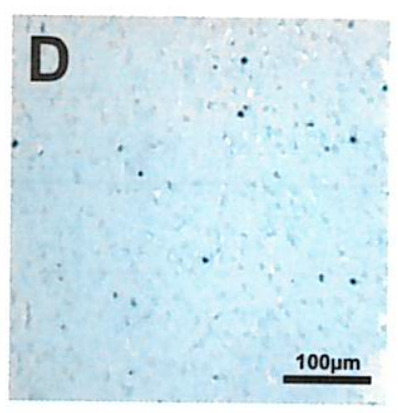

Melatonin

$15 \mathrm{mg} / \mathrm{kg}$ over $6 \mathrm{~h}$ 


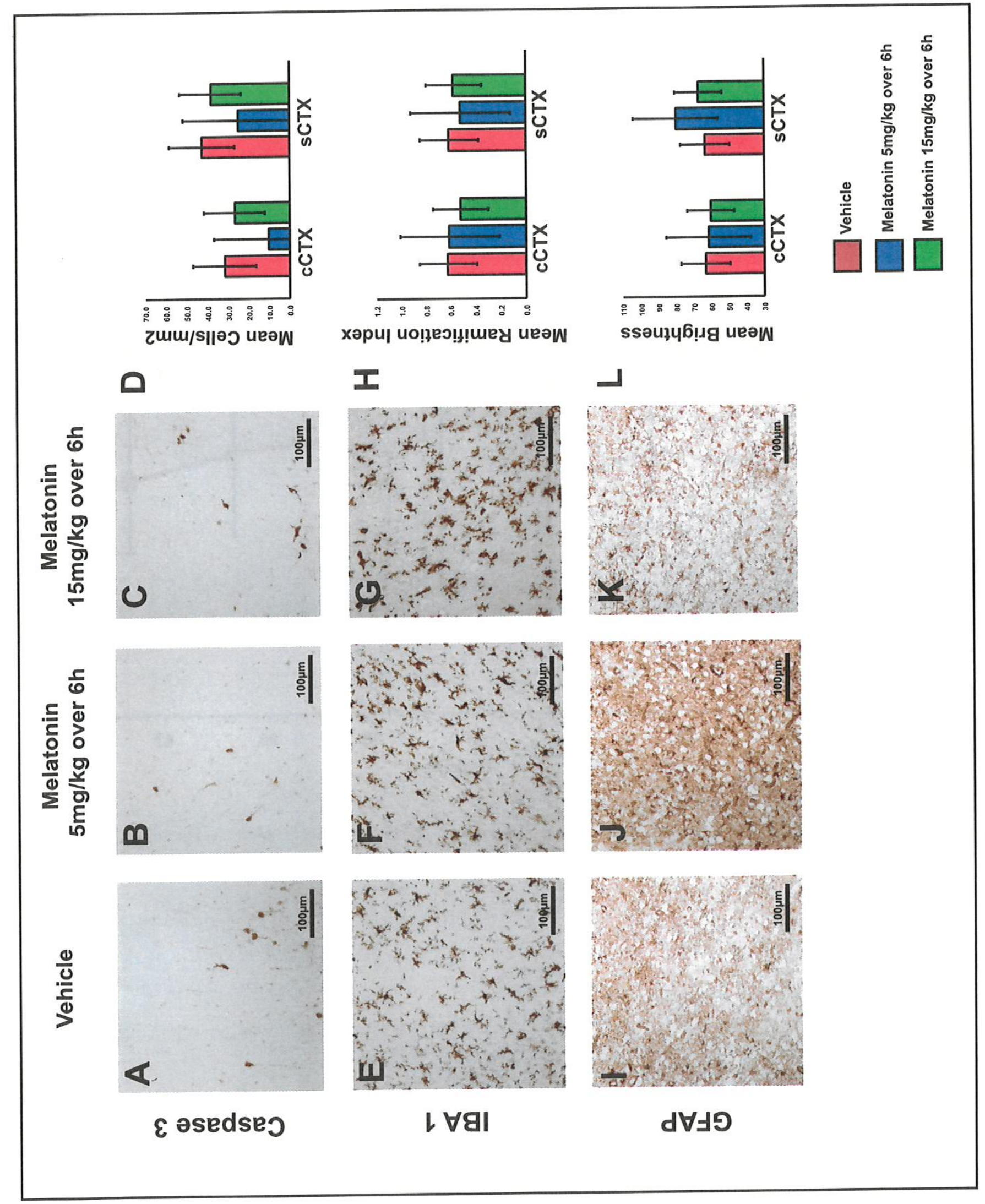




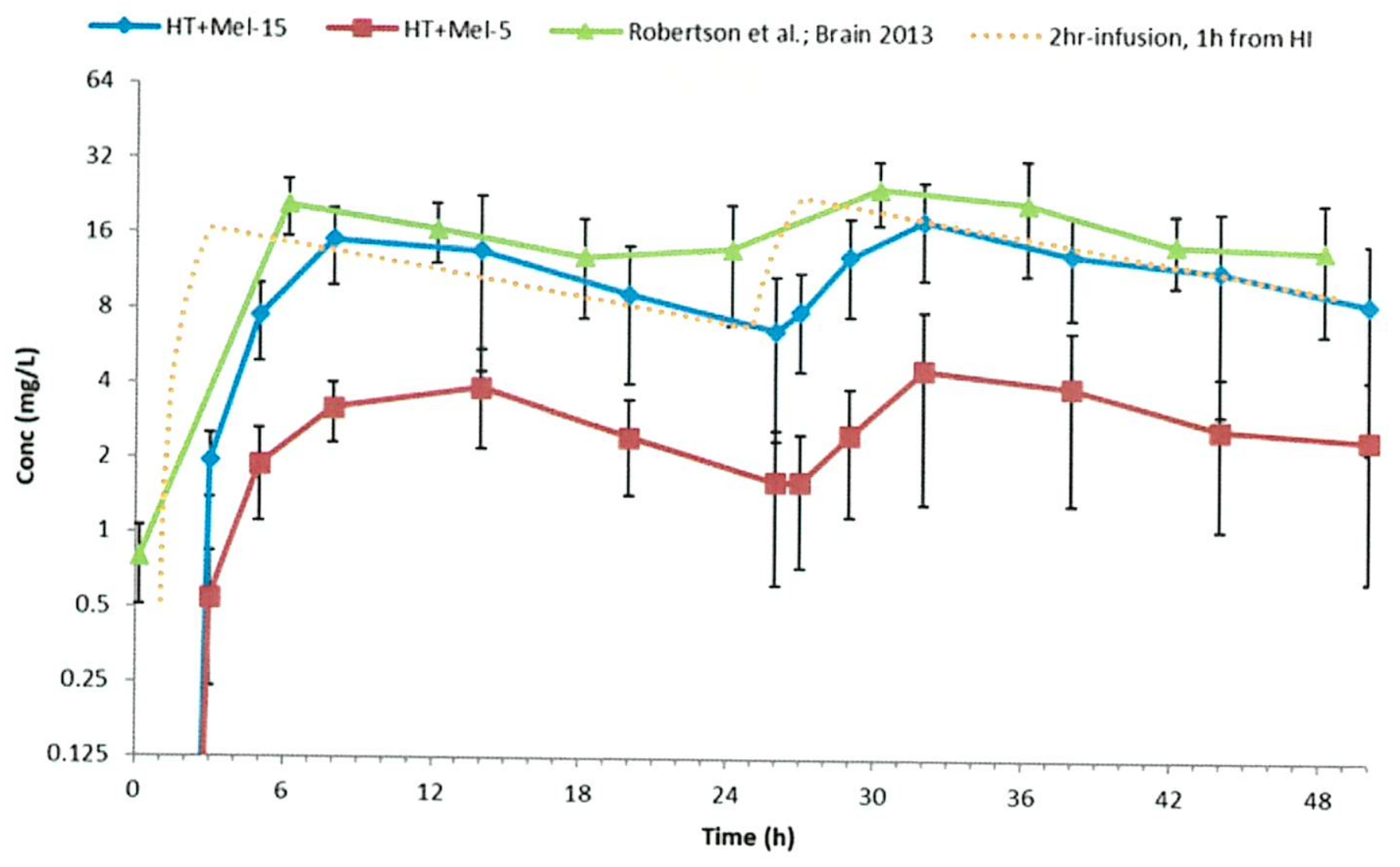




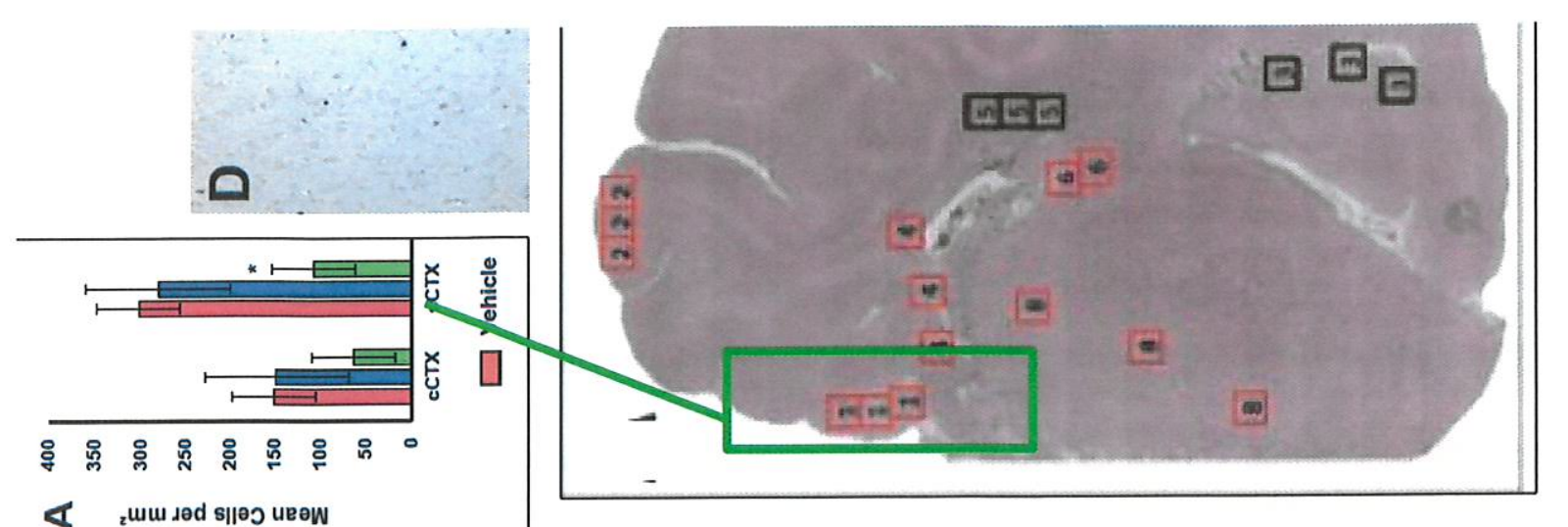

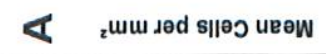

$\stackrel{\frac{c}{20}}{\gtrless}$
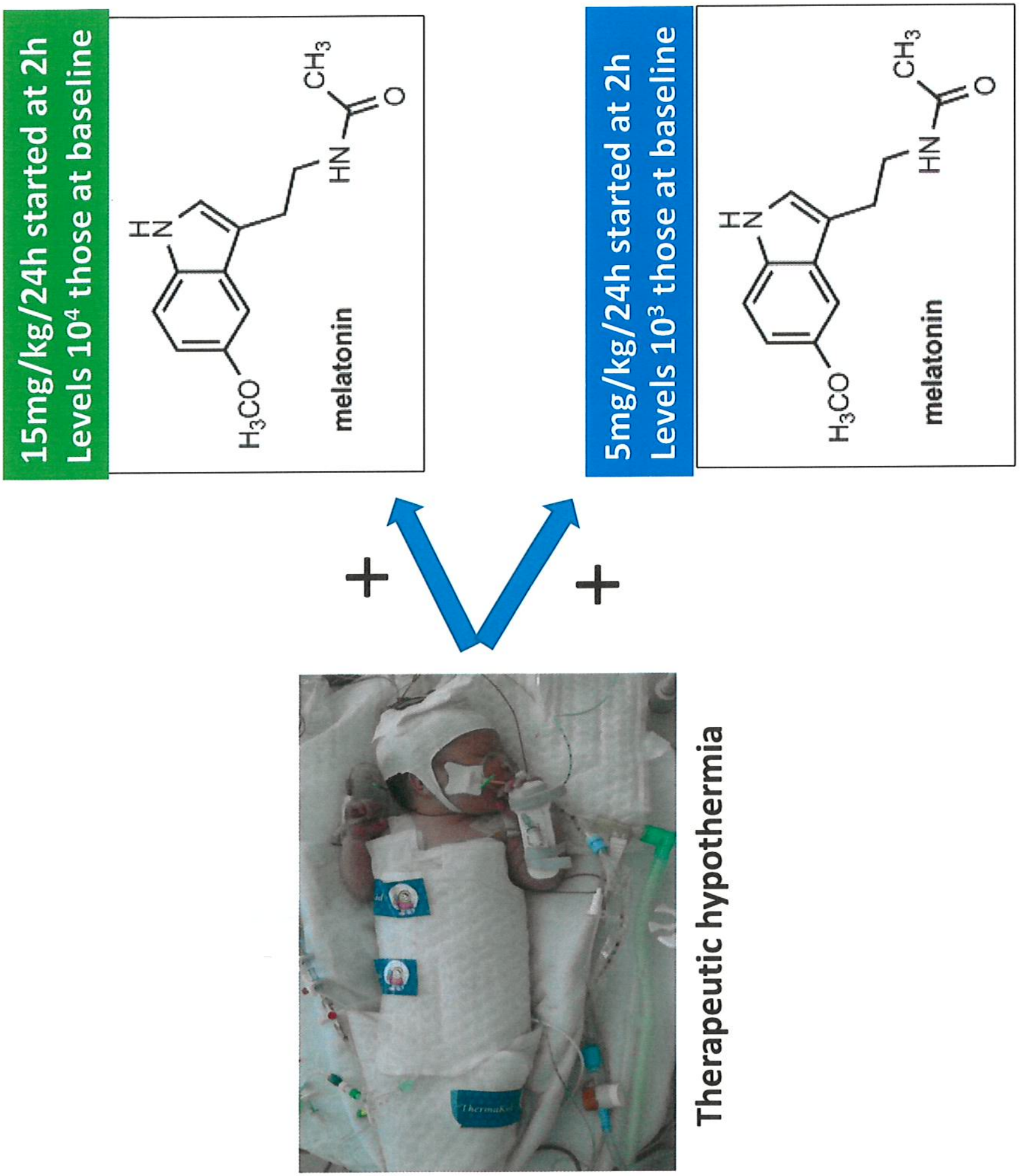

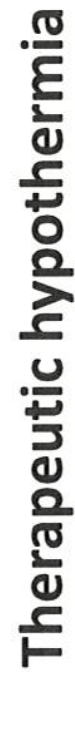




\section{Highlights}

1. $15 \mathrm{mg} / \mathrm{kg} / 24 \mathrm{~h} \mathrm{IV}$ melatonin given with cooling appears safe with no effect on BP

2. Compared to cooling, $15 \mathrm{mg} / \mathrm{kg} / 24 \mathrm{~h}$ melatonin started at $2 \mathrm{~h}$, reaching therapeutic levels by $8 \mathrm{~h}$, led to sensorimotor cortex protection

3. Compared to cooling, $5 \mathrm{mg} / \mathrm{kg} / 24 \mathrm{~h}$ melatonin started at $2 \mathrm{~h}$ did not reach therapeutic levels and was not protective

4. Augmentation of cooling protection with melatonin is dependent on plasma levels

5. PK modelling suggests that $18 \mathrm{mg} / \mathrm{kg}$ melatonin started at $1 \mathrm{~h}$ given over $2 \mathrm{~h}$ would reach therapeutic levels by $3 \mathrm{~h}$ 